\title{
DEFERENCIA INTERNACIONAL Y DISCRECIÓN NACIONAL Bajo El PaCto InTERnacional De Derechos Civiles Y Políticos*
}

\section{Pablo Contreras VásQuez**}

RESUMEN: El texto propone una reconstrucción dogmática de la jurisprudencia del Comité de Derechos Humanos, en materia de deferencia internacional y discreción de las autoridades nacionales. Primero, se analiza cómo el Comité ha evitado emplear de la doctrina europea del margen de apreciación estatal. Segundo, mediante la revisión de grupos de casos, se constata que el Comité elabora estándares propios de revisión internacional que van desde un escrutinio estricto a razones de deferencia. El artículo concluye que el Comité de Derechos Humanos ha desarrollado una jurisprudencia casuística de deferencia en la que se pueden identificar espacios para la discreción nacional.

PALABRAS CLAVE: Margen de apreciación - Deferencia - Discrecionalidad nacional - Comité de Derechos Humanos - Pacto de Derechos Civiles y Políticos.

\section{NATIONAL DISCRETION AND INTERNATIONAL DEFERENCE UNDER THE INTERNATIONAL COVENANT ON CIVIL AND POLITICAL RightS}

ABSTRACT: The paper offers a doctrinal reconstruction of the $\mathrm{Hu}-$ man Rights Committee's jurisprudence on national discretion and international deference. First, it analyzes how the Committee has avoided the use of the European "margin of appreciation" doctrine. Second, the paper reviews cases in which the Committee has developed particular deference

Fecha de recepción: 2 de diciembre de 2012.

Fecha de aceptación: 11 de abril de 2014.

** Licenciado en Ciencias Jurídicas y Sociales, Universidad Alberto Hurtado. Abogado. Magíster en Gobierno y Sociedad, Universidad Alberto Hurtado. Máster en Derecho (LL.M.), Mención en Derecho Internacional de los Derechos Humanos, Northwestern University. Candidato a Doctor en Derecho (S.J.D.), Northwestern University. Profesor de la Universidad Alberto Hurtado. Correo electrónico: pcontreras@nlaw.northwestern.edu. Todas las traducciones del inglés al español corresponden a traducciones propias del autor, salvo que se exprese lo contrario. El autor desea agradecer a Viviana Villalobos por su asistencia en las citas bibliográficas. El resultado final es de exclusiva responsabilidad del autor. 
standards, from strict scrutiny to those giving latitude to national authorities. It concludes by asserting that the Committee has granted discretion to domestic bodies, though only on case-by-case basis.

KEY WORDS: Margin of appreciation - Deference - National discretion - Human Rights Committee - International Covenant on Civil and Political Rights.

\section{INTRODUCCIÓN}

La discreción nacional en la limitación de derechos humanos y en la implementación de tratados internacionales, constituye uno de los últimos bastiones de la soberanía estatal. La determinación del contenido concreto de los derechos humanos y la supervisión internacional sobre las restricciones que estos sufren a nivel interno, permite conocer hasta qué punto tales derechos son protegidos. En otras palabras, la definición última de los derechos, depende de su interpretación y aplicación dialógica entre autoridades nacionales y entidades supranacionales de revisión.

A partir de esa premisa, se hace necesario estudiar el grado de discreción que poseen las autoridades nacionales en la protección y limitación de los derechos humanos. Parte de esta investigación, en clave comparada, se ha desarrollado profusamente en el sistema europeo e, incipientemente, en el sistema interamericano de protección a los derechos humanos ${ }^{1}$. La literatura dominante se ha enfocado en el análisis de la doctrina del "margen de apreciación" para comprender cómo opera la deferencia internacional en relación a la discreción nacional en materia del Derecho internacional de los derechos humanos ${ }^{2}$. El margen de apreciación (en adelante, "MDA") es una creación jurisprudencial del Tribunal Europeo

1 Contreras, Pablo (2012). "National discretion and international deference in the restriction of human rights: a comparison between the jurisprudence of the European and the Inter-American court of human rights" Northwestern Journal of International Human Rights: pp. 28 - 82. Disponible en http://scholarlycommons.law.northwestern.edu/cgi/viewcontent.cgi? article=1155\&context=njihr [fecha de consulta: 2 de noviembre de 2013]. Para el contexto europeo, véase Yourow, Charles (1996) The Margin of appreciation doctrine in the Dynamics of European Human Rights Jurisprudence. Londres: Ed. Kluwer Law International, pp. 15 y ss.; Arai-Takahashi, Yutaka (2002) The margin of appreciation Doctrine and the Principle of Proportionality in the Jurisprudence of the ECHR. Oxford: Intersentia, 145 pp.; Letsas, George (2006) "Two concepts of the margin of appreciation". Oxford Journal of Legal Studies. Vol. 26, pp. 705-732. Para el caso interamericano, véase Acosta et al. (coord.) (2012) El margen de apreciación en el sistema interamericano de Derechos Humanos: proyecciones regionales y nacionales. México: Instituto de investigaciones jurídicas UNAM, $385 \mathrm{pp}$.

2 García Roca, Javier (2007). "La muy discrecional doctrina del margen de apreciación nacional según el Tribunal Europeo de Derechos Humanos: Soberanía e Integración”. Teoría y Realidad Constitucional. Vol. 20. 117-143 pp. 
de Derechos Humanos (en adelante, "TEDH"). Esta doctrina ha sido definida como "la noción que cada sociedad tiene derecho a cierta latitud al resolver los conflictos inherentes entre derechos individuales e intereses nacionales o entre diferentes convicciones morales"3. Este estándar de revisión judicial ha sido empleado en numerosas oportunidades por el TEDH y, excepcionalmente, por la Corte Interamericana de Derechos Humanos ${ }^{4}$.

Sin perjuicio de la relevancia de la doctrina del margen de apreciación, la literatura no ha prestado atención a la forma como opera la discreción nacional en otros contextos 5 y, especialmente, bajo el marco del Pacto Internacional de Derechos Civiles y Políticos (en adelante, "Pacto" o "PIDCP") ${ }^{6}$. La relevancia de este tratado no puede ser minimizada: siendo parte de la Carta Internacional de Derechos Humanos ${ }^{7}$, puede ser ratificada por cualquier Estado y, potencialmente, puede llegar a cubrir a todas las personas alrededor del mundo ${ }^{8}$. El Pacto fue adoptado en 1966 y entró en vigencia diez años después. Actualmente, existen 167 Estados que son partes del tratado, un número que supera con creces a similares instrumentos internacionales en el ámbito regional ${ }^{9}$.

3 Benvenisti, Eyal (1999) "Margin of appreciation, consensus and universal standards", New York University Journal of International Law and Politics, Vol. 31: pp. 843-854. Disponible en http://www.pict-pcti.org/publications/PICT_articles/JILP/Benvenisti.pdf [fecha de consulta: 2 de noviembre de 2013], p. 843 y 844.

4 La Corte Interamericana de Derechos Humanos ha empleado explícitamente la doctrina del MDA en dos oportunidades. Véase Propuesta de Modificación a la Constitución Politica de Costa Rica relacionada con la Naturalización, Opinión Consultiva OC-4/84, (ser. A) No. 4 (Ene. 19, 1984) y Herrera Ulloa v. Costa Rica, Sentencia de objeciones preliminares, fondo, reparaciones y costas (ser. C) No. 107 (Jul. 2, 2004).

5 Quizás la única excepción se halla en LEGG, Andrew (2012) The margin of appreciation in international Human Rights Law, deference and proportionality. Oxford: Monographs in International Law, 272 pp.

6 Pacto Internacional de Derechos Civiles y Políticos ("Pacto"), abierto a la firma, Dic. 19, 1966, 999 U.N.T.S. 171.

7 La Carta Internacional de Derechos Humanos está compuesta por la Declaración Universal de Derechos Humanos (Res. A.G. 217A, O.N.U GAOR, 3a Ses., 1er plen. mtg., U.N. Doc. A/810 (Dec. 12, 1948)), el Pacto y el Pacto Internacional de Derechos Económicos, Sociales y Culturales, abierto a la firma, Dic. 19, 1966, 993 U.N.T.S. 3. Véase Humphrey, John (1976): "The international bill of rights: scope and implementation", Wm. \& Mary L. Rev., Vol. 17. pp. 527; Kabasakal, Zehra (2006): "Forging a Global Culture of Human Rights: Origins and Prospects of the International Bill of Rights", Hum. Rts. Q., Vol. 28: pp. 416; Young, Kirsten (2002): The Law and Process of the U.N, Human Rights Committee (Washington D.C., Hotei Publishing, 400 pp.

8 Conte, Alex; Burchill, Richard (2009) Defining civil and political rights: The jurisprudence of the United Nations Human Rights Committee, $2^{\text {nd }}$ ed. London, Ashgate Publishing, p. 3: "Ya que el Pacto es de potencial aplicación mundial, ocasionalmente es nombrado como uno de los instrumentos universales [de Naciones Unidas]."

9 La información sobre el Pacto puede ser encontrada en el sitio de la colección de tratados de Naciones Unidas (U.N.T.S.):

http://treaties.un.org/Pages/ShowMTDSGDetails.aspx?src=UNTSONLINE\&tabid=2\&m tdsg_no=IV-4\&chapter=4\&lang=en\#Participants [última visita efectuada Oct. 10, 2013] . 
El Comité de Derechos Humanos (en adelante, "Comité" o "CDD$\mathrm{HH}^{\prime}$ ") fue creado junto al Pacto y supervisa internacionalmente el cumplimiento de las obligaciones del mismo. Dicho órgano tiene tres tareas principales: supervisar los informes periódicos redactados por los Estados Partes del Pacto ${ }^{10}$; elaborar Observaciones Generales interpretando el sentido y alcance de las disposiciones del Pacto ${ }^{11}$; y decidir las denuncias de particulares en contra de los Estados Parte, regidas bajo el Primer Protocolo Facultativo al Pacto (en adelante, "Protocolo Facultativo") ${ }^{12}$. Solo los Estados que han ratificado este último tratado se encuentran bajo la jurisdicción del Comité, en relación a las denuncias de particulares ${ }^{13}$. A septiembre de 2013, 115 Estados son partes al Protocolo Opcional ${ }^{14}$.

El Comité decide la admisibilidad y el fondo de las comunicaciones o denuncias individuales a través de "observaciones" sobre el caso ${ }^{15}$. Dichas observaciones carecen de fuerza vinculante ${ }^{16}$. La misma expresión utilizada - "observaciones" - contrasta con la de sentencias, fallos o decisiones y ese habría sido el propósito deliberado de las partes contratantes en la elaboración del Protocolo Facultativo. El consenso doctrinal actual respalda tal lectura de las decisiones del Comité, pese a existir una tendencia minoritaria que busca fortalecer y afirmar la obligatoriedad de las observaciones para los Estados Parte del Protocolo Facultativo ${ }^{17}$. Esta

La Convención Europea de Derechos Humanos tiene 47 Estados Parte. Véase el sitio del Consejo de Europa: http://www.conventions.coe.int/Treaty/Commun/ChercheSig.asp?N $\mathrm{T}=005 \& \mathrm{CM}=8 \& \mathrm{DF}=08 / 02 / 2013 \& \mathrm{CL}=\mathrm{ENG}$ [última visita efectuada Oct. 10, 2013]. La Convención Americana de Derechos Humanos tiene 23 Estados Parte. Véase el sitio de la Organización de Estados Americanos: http://www.oas.org/dil/treaties_B-32_American_ Convention_on_Human_Rights_sign.htm [última visita efectuada Oct. 10, 2013].

10 Art. 40(1) del Pacto.

11 Art. 40(4) del Pacto. Todas las Observaciones Generales del Comité pueden encontrarse en el sitio de la Oficina del Alto Comisionado para los Derechos Humanos, de Naciones Unidas: http://www2.ohchr.org/english/bodies/hrc/comments.htm [última visita efectuada Oct. 10, 2013].

12 Protocolo Facultativo al Pacto Internacional de Derechos Civiles y Políticos ("Protocolo Facultativo"), entró en vigencia Mar. 23, 1976, 999 U.N.T.S. 302.

13 Art. 1 del Protocolo Facultativo: “[...] El Comité no recibirá ninguna comunicación que concierna a un Estado Parte en el Pacto que no sea parte en el presente Protocolo".

14 Véase el sitio de Colección de Tratados de Naciones Unidas (U.N.T.S.): http://treaties. un.org/Pages/ShowMTDSGDetails.aspx?src=UNTSONLINE\&tabid=2\&mtdsg_no=IV5\&chapter=4\&lang=en\#Participants [última visita efectuada Oct. 10, 2013].

15 Art. 5(4), Protocolo Facultativo.

16 Esta es la opinión dominante de la literatura sobre el Pacto y el Protocolo Facultativo. Véase NowaK Manfred (1993): U.N. Covenant on Civil and Political Rights: CCPR Commentary XXXIX, 710 pp; Mutua, Makau wa (1998). "Looking Past the Human Rights Committee: An Argument for De-Marginalizing Enforcement”. Buffalo Human Rights Law Review. Vol. 4, pp. 211-260, pp. 232-235. Helfer, Laurence; Slaughter, Anne-Marie (1997): “Toward a theory of effective supranational adjudication", Yale L.J., Vol. 107: pp. 273-351, p. 351; Conte / Burchill (2009) 36-37.

17 Sin perjuicio de ello, cfr. la opinión de académicos que afirman la naturaleza obligatoria de las Observaciones del Comité. Un resumen de ese debate se puede encontrar en DAVIDson, 
tendencia, sin embargo, no ha penetrado aún en el propio Comité. En el 2008, el Comité emitió la Observación General No. 33, donde autocomprendió su praxis interpretativa en términos similares a la de organismos judiciales, en el ámbito supranacional ${ }^{18}$. En razón de ello, sostuvo que las interpretaciones adoptadas bajo el procedimiento del Protocolo Facultativo son un "pronunciamiento autorizado" (autoritative determination o "determinación autoritativa", en inglés) que interpreta las disposiciones del Pacto ${ }^{19}$. Sin perjuicio de ello, el Comité fue cauto y no afirmó la fuerza vinculante de sus observaciones.

Sin perjuicio de la naturaleza no vinculante de las observaciones del Comité, existen buenas razones para el estudio de la discreción nacional en los estándares desarrollados por el Comité. Tanto el potencial alcance universal del Pacto como el número de Estados Parte del Pacto y del Protocolo Opcional, sugieren un impacto importante en la definición actual del sentido y la protección de los derechos humanos.

Este trabajo, por tanto, busca describir y analizar el grado de discreción nacional que otorga el Comité a las autoridades estatales y los estándares que ha ido desarrollando para efectos de ejecutar sus tareas de supervisión internacional. Tales estándares pueden ser reconstruidos dogmáticamente a partir de las Observaciones Generales y las observaciones recaídas en comunicaciones particulares, ambas interpretando el sentido y alcance de las disposiciones del Pacto.

Un aspecto relevante debe ser anotado desde el comienzo: el Comité no usa el concepto de MDA en cuanto tal, al menos, no bajo una fórmula textual. Tal como ser revisa más abajo, dicha doctrina ha sido literalmente citada solo en casos aislados, dentro del voto de mayoría de observaciones relacionadas con derechos de las minorías. No obstante, el Comité no ha incorporado el MDA como un concepto explícito dentro de su jurisprudencia $^{20}$. Ahora bien, el no referir explícitamente al MDA no ha impedido ni ha significado un obstáculo a reconocer determinada latitud en la restricción de derechos por parte de autoridades estatales. Por tanto, la discreción nacional, en el caso del Comité y el Pacto, no debe ser fraseada bajo el concepto del MDA, sino que bajo un esquema más amplio de comprensión que permita entender los estándares aplicables a deferencia internacional. El presente trabajo busca contribuir en dilucidar la forma

Scott (2002): Intention and effect: The legal status of the final views of the Human Rights Committee, in Litigating Rights. Perspectives from domestic and International Law. Oxford: Hart Publishing, 308-313 pp.

18 Observación General No. 33, Obligaciones de los Estados Parte con Arreglo al Protocolo Facultativo del Pacto Internacional de Derechos Civiles y Politicos, CCPR/C/GC/33, Nov. 5, 2008, 11. Id., 13.

Véase infra 1.1 . 
a través de la cual el Comité articula niveles o esferas de deferencia sin un empleo literal de la doctrina del MDA.

El texto se organiza de la siguiente forma. La sección 1 aborda el problema respecto al empleo del MDA por parte del Comité. Para ello, primero revisa los casos de derechos de las minorías, en donde el Estado alegó el MDA pero que el Comité resolvió sin recurrir explícitamente a la doctrina en comento. Segundo, se analizan los casos en que el Comité comienza a emplear conceptos de discreción nacional, específicamente, "margen de discreción". Esta parte examina la forma en que el Comité ha empleado tal estándar y cómo ha evolucionado. La sección 2 tiene un objetivo más ambicioso: se expande la exploración inicial, respecto a estándares de discreción nacional, y se aproxima inductivamente a la jurisprudencia del Comité, a efectos de reconstruir los estándares de supervisión y deferencia que emplea. Para ello, se aboca especialmente a los exámenes de proporcionalidad y necesidad que utiliza el Comité, en casos de libertad de expresión, libertad de conciencia y no discriminación, entre otras materias. El trabajo concluye que el Comité no ha sido particularmente claro en la definición de estándares de deferencia internacional y discreción doméstica. Sin perjuicio de ello, a partir del análisis de la casuística jurisprudencial, es posible identificar distintas esferas de discreción, especialmente, cuando interpreta las cláusulas de razonabilidad, arbitrariedad o necesidad.

\section{1) LA DoCTRINA DEL MDA EN LA JURISPRUdenCIA DEL COMité}

El Comité no ha incorporado explícitamente la doctrina del MDA y, sin embargo, ha reivindicado esferas de discreción nacional. La aproximación del Comité ha seguido una casuística escasamente sistemática de distintas hipótesis de discreción doméstica, lo que dificulta la tarea de definir estándares claros de deferencia internacional en esta materia. Esta sección busca explicar cómo el Comité se ha negado ha aplicar literalmente el MDA en casos de derechos de las minorías pero, no obstante, ha adoptado distintos estándares que se asemejan al contenido normativo de tal doctrina. A partir de ello, da cuenta de algunas de las formas en virtud de las cuales el Comité ha autorizado la discreción a las autoridades nacionales.

\section{1) RECHAZO A LA APLICACIÓN LITERAL DE LA DOCTRINA DEL MDA}

El Comité se ha negado a incorporar explícitamente la doctrina del MDA. Algunos Estados Parte han respondido las comunicaciones 
individuales en contra de ellos y han alegado el MDA como uno de los fundamentos jurídicos para restringir ciertos derechos bajo el Pacto ${ }^{21}$. A pesar de ello, el Comité no ha incorporado la doctrina en cuanto tal. En algunos de los casos que aquí se revisan, respecto de los derechos de las minorías establecidos en el artículo 27 del Pacto $^{22}$, se observa cómo el Comité ha creado nuevos estándares de revisión judicial. Aun cuando no ha incorporado el uso literal del MDA, ha definido el alcance de las obligaciones del artículo 27 de manera tal que permite cierta deferencia para las autoridades nacionales. Esto se explica a continuación.

Las comunicaciones individuales sobre la potencial violación del artículo 27 del Pacto son particularmente útiles para explicar el reemplazo del MDA por estándares alternativos de deferencia internacional. Dicho precepto establece el derecho de las minorías a gozar de su "propia vida cultural, a profesar y practicar su propia religión y a emplear su propio idioma." En Ilmari Länsman et al. v. Finlandia (“Länsman I'), el gobierno alegó que los Estados son soberanos y libres para desarrollar y promover actividades comerciales. Los autores de la comunicación eran criadores de renos de un particular grupo étnico en Finlandia y sostenían que su derecho a gozar de su propia cultura sería afectada si se autorizaba una cantera para la extracción de piedra en ciertas áreas de su territorio comunitario. La empresa, además, tenía que transportar la piedra a través de algunas de las vallas que cercaban a los renos. En opinión de los peticionarios, tanto la extracción como el transporte de las piedras afectaba las actividades de rebaño y pastoreo de renos.

En la interpretación de los presupuestos del artículo 27 del Pacto -especialmente, en relación a la restricción del derecho- Finlandia alegó que un "margen de discreción debe ser reservado a las autoridades nacionales" 23 . El Estado citó la doctrina del TEDH en la materia y afirmó que "el juez nacional se encuentra en una mejor posición que el juez internacional para tomar una decisión” de esta naturaleza ${ }^{24}$. En este caso, Finlandia consideró que las autoridades administrativas y los tribunales nacionales habían legalmente otorgado los permisos necesarios para la

21 Véase Ilmari Länsman et al. v. Finlandia, Comm. No. 511/1992, Nov. 8, 1994, 7.13; Kall v. Polonia, Comm. No. 552/1993, Jul. 7, 1997, 10.3; Mohamed El-Hichou v. Dinamarca, Comm. No. 1554/2007, Jul. 7, 2010, 4.2; Panagiotis A. Schremelis et al. v. Grecia, Comm. No. 1507/2006, Oct. 25, 2010, 8.2.

22 "Artículo 27. En los Estados en que existan minorías étnicas, religiosas o lingüísticas, no se negará a las personas que pertenezcan a dichas minorías el derecho que les corresponde, en común con los demás miembros de su grupo, a tener su propia vida cultural, a profesar y practicar su propia religión y a emplear su propio idioma."

23 Ilmari Länsman et al. v. Finlandia (“Länsman P”), Comm. No. 511/1992, Nov. 8, 1994, en 7.13 .

$24 \quad$ Id 
operación de la empresa. Sin embargo, el Comité no acogió tal razonamiento y sostuvo lo siguiente:

“Un Estado puede comprensiblemente buscar estimular el desarrollo o permitir actividades empresariales. El marco de esta libertad para hacerlo no debe ser fijado en referencia a un margen de apreciación, sino que en relación a las obligaciones que emanan del articulo 27 . El artículo 27 exige que un miembro de una minoría no sea privado de su derecho a gozar de su propia cultura. Por tanto, medidas cuyo impacto signifiquen una negación del derecho, no serán compatible con las obligaciones bajo el artículo 27. Sin embargo, aquellas medidas que tengan un impacto limitado en el modo de vida de las personas pertenecientes a una minoría no constituirían necesariamente una negación bajo el artículo $27 " 25$.

Es importante hacer notar dos elementos. Primero, el Comité no incorpora explícitamente la doctrina del MDA para examinar la conducta del Estado Parte, en conformidad a lo dispuesto en el Pacto. Por el contrario, el Comité se aboca a escudriñar el contenido normativo del artículo 27 y las obligaciones internacionales que genera. En segundo lugar, el Comité no niega la posibilidad que el Estado imponga restricciones legítimas al derecho establecido en el artículo 27. Esto es fundamental para un estudio de la deferencia internacional: pese a que el Comité no aplica la doctrina del MDA -tal como ha sido desarrollado por el TEDH- la decisión igualmente habilita cierto margen de discrecionalidad estatal en la promoción de actividades económicas. Los Estados deben proteger el derecho establecido en el artículo 27 y solo un "impacto limitado en el modo de vida" de las personas que pertenecen a una minoría sería admisible, bajo la supervisión internacional del Comité. El test de "impacto limitado" implica, básicamente, una examinación de grado en atención al caso concreto, en virtud del cual se atiende a los factores que afectan la forma de vida de las minorías. No podría, por tanto, ser analizado en abstracto. En cualquier caso, dichas restricciones siempre quedan bajo la competencia del Comité, a efectos de su escrutinio internacional. En Länsman I, el Comité sostuvo que "la actividad en cuestión no era sustancial como para impactar en el derecho a gozar de la propia cultura de los peticionarios" 26 . En consecuencia, se determinó que no hubo una violación del artículo 27.

25 Ilmari Länsman et al. v. Finland, cit., 9.4, énfasis agregado.

26 Conte / Burchill (2009) 277. 
La decisión afectó la forma en que los casos de derechos de la minorías serán decididos el Comité. Por ejemplo, en un caso promovido por un grupo de maoríes en contra de Nueva Zelanda, se alegó que el Estado violó el artículo 27 del Pacto, al modificar o caducar legalmente los derechos y las cuotas de pesca actualmente en vigor ${ }^{27}$. El Comité afirmó que "el derecho a gozar de la propia cultura no puede ser determinado in abstracto y que debe situarse en un contexto" 28 . Para examinar la compatibilidad de la nueva regulación de pesca con el Pacto, el Comité recordó lo que había señalado respecto de la doctrina del MDA en Länsman ${ }^{29}$. Luego de considerar los hechos del casos, el Comité consideró que no había violación del artículo 27. En un caso posterior, Jouni Lansman et al. v. Finlandia ("Länsman IP"), el Estado argumentó que las limitaciones impuestas al ejercicio del derecho del artículo 27 para desarrollar actividades de explotación de recursos naturales, eran válidas puesto que solo ocasionaban un "impacto limitado" en el derecho de las minorías ${ }^{30}$. El caso involucraba la supervivencia de la ganadería de renos, como parte de la cultura de la minoría sami en Finlandia. Nuevamente, la Observación del Comité examinó el alcance de las obligaciones del Estado bajo el artículo 27, sin referencia alguna al MDA. El Comité consideró que las medidas adoptadas por el Estado no representaba una amenaza para el derecho de los peticionarios ${ }^{31}$.

Estos son los únicos casos en que la expresión "margen de apreciación" aparece en su literalidad en el razonamiento del Comité. Las Observaciones, sin embargo, denotan la reticencia a aplicar, al menos literalmente, la doctrina del $\mathrm{MDA}^{32}$. Es interesante observar que dicha doctrina no es citada fuera de los casos del artículo 27 del Pacto ${ }^{33}$. Sin perjuicio de lo anterior, el Comité ha desarrollado un estándar para supervisar las potenciales vulneraciones al artículo 27. El test corresponde a evaluar

Apirana Mahuika et al. v. Nueva Zelanda, Comm. No. 547/1993, Oct. 27, 2000.

Id., 9.4.

Id., citando Ilmari Länsman et al. v. Finlandia, cit., 9.4.

Jouni Länsman et al. v. Finlandia, Comm. No. 671/1995, Oct. 30, 1995, 6.5-6.7

$I d$., 10.7. El Comité, sin embargo y como obiter dictum, manifestó su preocupación sobre la práctica del Estado. Específicamente, señaló que tenía conocimiento "de que se estaba planificando e implementando otras explotaciones de gran escala afectando el medio ambiente, como la extracción de piedra, en el área en donde el pueblo Sami habita. Aunque en la presente comunicación, el Comité ha concluido que los hechos del caso no revelan una violación de derechos de los autores, el Comités estima importante señalar que el Estado Parte debe tener en cuenta que, si bien tales actividades aisladamente pueden no configurar una violación del artículo 27, estas, en conjunto, pueden menoscabar los derechos de los sami a gozar de su propia cultura" (Id.).

Véase a LEGG, Andrew (2012) 34-35. (afirmando que "la terminología del margen de apreciación parece haber sido evitada" y que los "Estados han continuado apoyando tesis de deferencia ante el [Comité] pero, en general, han evitado utilizar la terminología de 'margen de apreciación'”).

Excepto por las ocasiones invocaciones que hacen los Estados Parte. Véase supra nota 21. 
el "impacto" que determinadas actividades económicas o regulaciones estatales pueden tener sobre los derechos de las minorías. El "impacto limitado" habilita una esfera de discreción nacional en la armonización de los derechos de las minorías con el desarrollo económico. Debe destacarse que el Comité no encontró una violación del derecho en cuestión en ninguna de las Observaciones citadas más arriba ${ }^{34}$. La conclusión refuerza la latitud que el Comité ha reservado a los Estados Parte en la regulación de las actividades económicas que puede impactar en la vida y cultura de grupos minoritarios.

\section{2) EL CONCEPTO DE "MARGEN DE DISCRECIÓN"}

Quizás el más claro ejemplo de deferencia internacional se puede encontrar en la Observación de Herzberg et al. v. Finlandia ${ }^{35}$. Los autores de la comunicación denunciaban cinco situaciones en las que las autoridades nacionales habían restringido la libertad de expresión ya sea censurando a programas de radio y televisión que versaban sobre asuntos de homosexualidad o sancionando a sus participantes ${ }^{36}$. El Código Penal de Finlandia, en su momento, castigaba las conductas que "violaran la moral sexual" y la promoción de "comportamiento indecente entre personas del mismo sexo." Dicha legislación configuraba el marco jurídico para perseguir y acusar penalmente a los editores de los programas de radio y televisión que difundiesen asuntos relacionados con la homosexualidad y habilitaba la censura de las radioemisoras y las señales de televisión ${ }^{37}$. Los autores de la comunicación cuestionaron la validez de la legislación ante el Comité, pero este se negó a una revisión in abstracto de la compatibilidad de la norma nacional con el Pacto ${ }^{38}$. En relación al fondo del asunto, el Comité examinó la restricción del derecho con las obligaciones internacionales del Estado Parte. Dos shows fueron censurados y el Estado argumentó que tal medida era necesaria para proteger la "moral pública," de acuerdo a lo dispuesto en el artículo 19.3, letra b) del Pacto ${ }^{39}$. El Comité reconoció que requería de más información sobre el contenido de los

34 Sobre el récord de casos de pueblos indígenas ante el Comité, revísese a MacKaY, Fergus (2001): "Guía sobre los derechos de los pueblos indígenas y el comité de los derechos humanos de las Naciones Unidas". Disponible en: http://odhpi.org/wp-content/ uploads/2012/08/COMITE-DDHH-Y-PUEBLOS-INDIGENAS.pdf [fecha de consulta: 4 de julio de 2013], 56 pp..

35 Hertzberg et al. v. Finlandia, Comm. No. 61/1979, Abr. 2, 1982.

$36 \quad$ Id., 2.1 .

$37 \quad$ Id., 2.2-2.5.

$38 \quad$ Id., 9.3.

39 "Artículo 19.

1. Nadie podrá ser molestado a causa de sus opiniones.

2. Toda persona tiene derecho a la libertad de expresión; este derecho comprende la libertad de buscar, recibir y difundir informaciones e ideas de toda índole, sin consideración de 
shows censurados para emitir una opinión fundada. No obstante, señaló claramente que la comprensión de la "moral pública difiere ampliamente" y que "no existe un estándar universal común aplicable" en este asunto ${ }^{40}$. La Observación dispuso que "un cierto margen de discreción debe ser reservado a las autoridades nacionales responsables," admitiendo que algunas restricciones estarían justificadas para prevenir los "dañinos efectos sobre menores [que] no pueden ser excluidos" 41 .

En Hertzberg, el Comité empleó el concepto de "margen de discreción" para justificar la restricción a la libertad de expresión de los autores de la comunicación. Aunque diferente en su nomenclatura, el contenido del concepto se asemeja a la doctrina del MDA desarrollada por el TEDH. En efecto, el "margen de discreción" provee de una esfera de discreción nacional sobre la definición del contenido de la moral como finalidad legítima para restringir derechos humanos, tales como la libertad de expresión. Algunos autores han señalado que el Comité ha "coqueteado" con la doctrina del MDA en este caso en particular ${ }^{42}$. Tal posición tiene cierto apoyo en la misma jurisprudencia del TEDH, que ha actuado deferentemente respecto de las autoridades nacionales en casos sobre blasfemia y la protección de la moral pública ${ }^{43}$. En dichos casos, el TEDH decidió deferentemente, reservando el juicio inicial -en estas materias- a las autoridades internas pero, a la vez, reservándose las facultades de supervisión internacional.

La ratio decidendi de Hertzberg, ha sido considerada como una de las escasas oportunidades en que el Comité ha aplicado un análisis de MDA en la interpretación del contenido normativo de los derechos del Pacto. Andrew Legg es uno de los autores en esta línea ${ }^{44}$. Conte y Burchill, refiriéndose en general a la aplicación del MDA en las Observaciones del Comité, estiman que en los casos en que el Comité ha brindado deferen-

fronteras, ya sea oralmente, por escrito o en forma impresa o artística, o por cualquier otro procedimiento de su elección.

3. El ejercicio del derecho previsto en el párrafo 2 de este artículo entrańa deberes y responsabilidades especiales. Por consiguiente, puede estar sujeto a ciertas restricciones, que deberán, sin embargo, estar expresamente fijadas por la ley y ser necesarias para:

a) Asegurar el respeto a los derechos o a la reputación de los demás;

b) La protección de la seguridad nacional, el orden público o la salud o la moral públicas.

Id., 10.3

Id., 10.4 .

Conte / Burchill (2009) 43. En una posición similar Shany, Yuval (2006): “Toward a general margin of appreciation doctrine", International Law European Journal of International Law, Vol. 16: 907-929 pp. Disponible en: http://www.ejil.org/pdfs/16/5/330.pdf [fecha de consulta: 2 de noviembre de 2013], 929 p.

43 En los casos de blasfemia, véase Otto-Preminger-Institut v. Austria, App. No. 13470/87, Sept. 20, 1994 y Wingrove v. United Kingdom, App. No. 17419/90, Nov. 25, 1996. En materia de moralidad pública, el caso emblemático es Handyside v. United Kingdom, App. No. 5493/72, Dic. 7, 1976.

44 LegG (2009) 33-34. 
cia internacional no pueden ser equiparados en plenitud con el MDA del $\mathrm{TEDH}^{45}$. Otros autores comparten esta posición ${ }^{46}$. Parecería ser, entonces, que la interpretación de la "moral pública" y el mentado "margen de discreción” en Hertzberg debe ser entendido en relación a los hechos del caso y atendiendo siempre a su antigüedad -fue decidido en 1982-.

En decisiones posteriores, el Comité ha reducido la discreción reservada a las autoridades estatales en la apreciación de la moral, como causal restrictiva de derechos. En Toonen v. Australia, el Comité sostuvo que "no [se] puede aceptar que [...] las cuestiones de moral constituyan exclusivamente un asunto de preocupación para el país en cuestión, ya que ello permitiría que se eliminase de la lista de asuntos que ha de examinar el Comité un número potencialmente grande de leyes que representan una injerencia en la vida privada" ${ }^{47}$. Al interpretar la cláusula de moral del artículo 19, el Comité explicó que dicho concepto debe ser siempre entendido "en el contexto de la universalidad de los derechos humanos y el principio de no discriminación" ${ }^{48}$. No hay referencia alguna al denominado "margen de discreción" en la Observación.

Recientemente, al tratar el problema de libertad de expresión y minorías sexuales, el Comité fortaleció el estándar de revisión internacional el año pasado. En Fedotova v. Federación Rusa, una lesbiana fue condenada a pagar una multa por exhibir letreros apoyando conductas homosexuales en las cercanías de un colegio ${ }^{49}$. La legislación nacional prohibía estas conductas ${ }^{50}$. El Comité citó su Observación General No. 34 sobre Libertad de Expresión y procedió a revisar la restricción al derecho en cuestión y la potencial discriminación legal en contra de activistas LGBT. El Estado invocó la protección de la moral y la salud públicas y los derechos y los legítimos intereses de menores, para efectos de justificar la legislación. Sin embargo, el Comité estimó que Rusia no había demostrado que "una restricción de la libertad de expresión en relación con la 'propaganda de homosexualidad' frente a menores -en contraposición a la propaganda de heterosexualidad o de la sexualidad en general- se basara en criterios razonables y objetivos. Es más, no existe evidencia que demuestre la existencia de factores justificando tal distinción" 51 . Es

45 Conte/ Burchill (2009) 44.

46 Véase, por ejemplo, Gandhi (1998) 14 (citando a Rosalyn Higgins, quien sugiere que el Comité se ha negado a aplicar la doctrina del MDA).

47 Toonen v. Australia, Comm. No. 488/1992, Mar. 31, 1994, 8.6.

48 Observación General No. 34: General Comment No. 34. Artículo 19: Libertad de Opinión y Libertad de Expresión, CCPR/C/GC/34, Sept. 12, 2011, 32.

49 Fedotova v. Russian Federation, Comm. No. 1932/2010, Oct. 31, 2012.

$50 \quad$ La ley disponía lo siguiente: "Conductas públicas con objetivos de propaganda de la homosexualidad (actos sexuales entre hombres o lesbianismo) frente a menores, será castigado con una multa administrativa que va desde mil quinientos y dos mil rublos." Citado en id., 2.3. Id., 10.6 . 
importante destacar que el Comité reconoció el rol del Estado en la protección del bienestar de los menores pero determinó que, en este caso, el Estado no acreditó que las medidas restrictivas fueren necesarias para la protección de tal fin ${ }^{52}$. El derecho de la peticionaria fue afectado por expresar "su identidad sexual" y ello constituyó una violación al artículo 19 del Pacto, incluso si -como alegó Rusia- se hubiese intentado involucrar a menores en discusiones de temas relacionados con la homosexualidad ${ }^{33}$. Tanto Toonen como Fedotova demuestran cómo el estándar de supervisión del Comité ha ido cambiando. Al interpretar la cláusula de moral como límite a la libertad de expresión, el Comité intensifica su escrutinio y reduce la esfera de discreción nacional para restringir tal derecho.

\section{3) CONCLUSIÓN}

El Comité ha rechazado la aplicación de la doctrina del MDA, al menos, en su fórmula literal. En lo casos relacionados con los derechos de las minorías, se observa que si bien el Comité se ha referido al MDA, este ha desechado su empleo y ha procedido a fijar estándares autónomos para la revisión del cumplimiento de las obligaciones del Pacto. Como se trata de los pocos casos en que el concepto de MDA aparece explícitamente, es dable concluir que el Comité ha preferido evitar su incorporación en sus Observaciones.

Sin perjuicio de ello, en materia del derecho a gozar de la propia cultura, el Comité ha desarrollado estándares autónomos que sí reservan esferas de discrecionalidad a las autoridades nacionales. En Länsman I, el Comité permitió restricciones al artículo 27 del Pacto, siempre y cuando tales medidas solo supongan un "impacto limitado" en la forma de vida de tales grupos. Por tanto, los Estados tienen cierta discrecionalidad en la armonización de, por un lado, el desarrollo económico con, por el otro, los derechos de las minorías. En cualquier caso, tal discreción no ha sido estructurada bajo la doctrina del MDA.

En otros casos, el Comité ha usado el concepto de "margen de discreción" que pareciera ser similar a la doctrina del MDA. En sus primeras Observaciones, el Comité decide comunicaciones relacionadas a los derechos de personas LGBT, otorgando deferencia a los Estados Partes en la regulación nacional. Hertzberg es el caso que demuestra esta doctrina. Sin embargo, la jurisprudencia cambia ostensiblemente con el paso de los años, reduciendo el espacio de discreción nacional. Tanto Toonen como Fedotova muestran cómo se ha encogido la deferencia internacional en estas materias.

$\begin{array}{ll}52 & \text { Id., } 10.8 . \\ 53 & \text { Id. }\end{array}$ 
La revisión de estos casos da pie para investigar otros estándares que emplea el Comité en su jurisprudencia, con el objeto de articular el escrutinio internacional y la discreción estatal. La siguiente sección se aboca a ello.

\section{2) DISCRECIÓN NACIONAL Y RESTRICCIÓN DE DERECHOS}

Los niveles de escrutinio internacional usados por el Comité pueden ser mejor comprendidos al revisar las comunicaciones en que este ha tenido que examinar si una medida nacional fue necesaria o proporcional bajo el Pacto. Observaciones que resuelven casos difíciles sobre materias de seguridad nacional, libertad de expresión, libertad religiosa y el derecho a la igualdad y la prohibición de discriminación, constituyen cuestiones paradigmáticas donde se discute la aplicación y contenido de cláusulas como "arbitrario", "razonable", "necesario" y/o "proporcional". La aplicación concreta de estas cláusulas permite discernir los espacios de deferencia internacional.

Esta sección intenta sistematizar las Observaciones del Comité con el propósito de identificar los estándares de discreción. Varios de estos casos muestran claras violaciones a los derechos humanos. Sin embargo, el Comité hace ciertos esfuerzos en definir la intensidad de la supervisión internacional y los márgenes de discreción nacional. Una de las mejores formas de aproximarse a este tema es revisando, primero, las condiciones a partir de las cuales la restricción de un derecho es compatible con las obligaciones del Pacto. A partir de ahí, el paper se enfoca en el análisis de los casos principales sobre seguridad nacional, libertad de expresión, libertad religiosa y prohibición de discriminación.

\section{1) Presupuestos del PaCto para Restringir VÁlidamente DERECHOS}

El Pacto ha sido diseñado de manera tal que permite la restricción de determinados derechos humanos. Algunos derechos han sido redactados en términos incondicionados, esto es, sin una cláusula de limitación. La prohibición de tortura, esclavitud y servidumbre ${ }^{54}$, calzan bajo esta descripción. Por otro lado, algunos derechos tienen cláusulas expresas que habilitan su restricción. Aquí encontramos la libertad religiosa ${ }^{55}$, libertad

\footnotetext{
54 "Artículo 7. Nadie será sometido a torturas ni a penas o tratos crueles, inhumanos o degradantes. En particular, nadie será sometido sin su libre consentimiento a experimentos médicos o científicos".

55 "Artículo 18.

1. Toda persona tiene derecho a la libertad de pensamiento, de conciencia y de religión; este derecho incluye la libertad de tener o de adoptar la religión o las creencias de su elección, así
} 
de expresión ${ }^{56}$ y el derecho de asociación ${ }^{57}$, entre otros derechos ${ }^{58}$. Algunas de las cláusulas restrictivas son compartidas entre derechos -tales como seguridad nacional o la moral-59 pero otras son específicas para ciertos derechos ${ }^{60}$. La estructura del texto del Pacto, así entendida, provee un base normativa para estructurar distintos estándares referentes a la discreción nacional.

El Pacto permite, además, la suspensión de sus obligaciones en casos de emergencia pública. Esta drástica medida, regulada en el artículo $4^{\circ}$, tiene requisitos especiales. Primero, está reservada solo para "situaciones excepcionales que pongan en peligro la vida de la nación" del Estado Parte. Segundo, contempla una exigencia de proporcionalidad ("en la medida estrictamente limitada a las exigencias de la situación"). Finalmente, tiene una regla explícita de prohibición de discriminación ("siempre que tales disposiciones no sean incompatibles con las demás obligaciones que les impone el derecho internacional y no entrañen discriminación alguna fundada únicamente en motivos de raza, color, sexo, idioma, religión u

como la libertad de manifestar su religión o sus creencias, individual o colectivamente, tanto en público como en privado, mediante el culto, la celebración de los ritos, las prácticas y la enseñanza.

2. Nadie será objeto de medidas coercitivas que puedan menoscabar su libertad de tener o de adoptar la religión o las creencias de su elección.

3. La libertad de manifestar la propia religión o las propias creencias estará sujeta únicamente a las limitaciones prescritas por la ley que sean necesarias para proteger la seguridad, el orden, la salud o la moral públicos, o los derechos y libertades fundamentales de los demás.[...]"

56 Supra nota 39.

57 "Artículo 22.

1. Toda persona tiene derecho a asociarse libremente con otras, incluso el derecho a fundar sindicatos y afiliarse a ellos para la protección de sus intereses.

2. El ejercicio de tal derecho solo podrá estar sujeto a las restricciones previstas por la ley que sean necesarias en una sociedad democrática, en interés de la seguridad nacional, de la seguridad pública o del orden público, o para proteger la salud o la moral públicas o los derechos y libertades de los demás. El presente artículo no impedirá la imposición de restricciones legales al ejercicio de tal derecho cuando se trate de miembros de las fuerzas armadas y de la policía. [...]"

58 Otros derechos con cláusulas limitativas: artículo 12 (libertad ambulatoria); artículo 14 (publicidad de los juicios) y artículo 21 (derecho de reunión pacífica).

59 Seguridad nacional y moral aparecen juntos en el artículo 12 (libertad ambulatoria); artículo 14 (publicidad de los juicios); artículo 19 (libertad de expresión); artículo 21 (derecho de reunión pacífica); y artículo 22 (derecho de asociación).

60 Por ejemplo, el artículo 14 establece el derecho a un juicio público pero puede ser restringido "interés de la vida privada de las partes" lo exija o si la "la publicidad pudiera perjudicar a los intereses de la justicia”, entre otras consideraciones. El artículo 19 permite restricciones de la libertad de expresión para asegurar el respeto de la "reputación de los demás". El artículo 20 establece una restricción general a la libertad de expresión, obligando a los Estados Parte a prohibir la propaganda de la guerra y toda "apología del odio nacional, racial o religioso que constituya incitación a la discriminación, la hostilidad o la violencia [...]." El artículo 22 permite que los Estados Parte fijen "restricciones legales" en el derecho de asociación de las Fuerzas Armadas. Finalmente, el derecho de participación política del artículo 25 prohíbe, en términos abstractos y genéricos, "restricciones indebidas". 
origen social") ${ }^{61}$. No obstante lo anterior, el artículo $4^{\circ}$ dispone que ocho derechos no pueden ser suspendidos en ningún caso: el derecho a la vida, la prohibición de tortura y de penas o tratos crueles, inhumanas o degradantes, la prohibición de esclavitud y servidumbre, la prohibición de la prisión por incumplimiento de obligaciones contractuales, el principio de legalidad en materia penal, el derecho a la personalidad jurídica, la libertad de pensamiento, conciencia y religión ${ }^{62}$. Estas reglas sobre la suspensión de derechos deben ser tomadas en consideración a la hora de determinar los estándares de supervisión internacional. Eso excede el objeto de este estudio, que se aboca a la restricción de derechos en situaciones de normalidad, pero deberá ser atendido en futuras investigaciones sobre la materia.

La reconstrucción doctrinal de los límites a los derechos presenta un panorama similar entre los presupuestos del Pacto y los que han sistematizado el Tribunal Europeo y la Corte Interamericana de Derechos $\mathrm{Hu}$ manos. En Europa se exigen tres presupuestos para la restricción válida de derechos: a) la restricción debe estar "prevista por la ley" ${ }^{63}$; la medida restrictiva debe perseguir uno más "finalidades legítimas" bajo el Convenio; c) y cualquier intervención con el ejercicio del derecho debe ser "necesaria en una sociedad democrática" ${ }^{4}$. El último presupuesto importa la aplicación del principio de proporcionalidad, en el examen y revisión de las medidas restrictivas de derechos. En América, la Corte Interamericana de Derechos Humanos ha adoptado un set de condiciones similares bajo la Convención. En su primera jurisprudencia, la Corte adoptó las mismas tres exigencias del Tribunal Europeo, para efectos de restricciones de derechos: estas deben haber sido prescritas por la ley, deben perseguir un objetivo legítimo bajo la Convención y deben ser necesarias en el marco de una sociedad democrática ${ }^{65}$. Algunos años atrás, la Corte modificó el test para las restricciones y agregó una nueva condición, al menos para los casos de libertad de expresión: estas deben ser "estrictamente proporcionales" al objetivo perseguido ${ }^{66}$.

\footnotetext{
61 Artículo 4(1) del Pacto.

62 Artículo 4(2) del Pacto.

63 Por ejemplo, en los artículo 8(2), 9(2) y 10(2) de la Convención Europea de Derechos Humanos.

64 El trabajo no aborda el problema de los límites "implícitos" o "inherentes" de derechos bajo la Convención Europea. Sobre esto véase Arai (2006) 342-348; Brage (2005) 131.

65 Claude-Reyes et al. v. Chile, Sentencia de fondo, reparaciones y costas (ser. C) No. 151, 8991 (Sept. 19, 2006). Esta decisión estableció de manera precisa los tres requisitos. Sentencias anteriores también fijaban requisitos similares, pero no eran claramente diferenciados, al menos analíticamente. Véase Herrera-Ulloa v. Costa Rica, cit., 101.1; Ricardo Canese v. Paraguay, Sentencia de fondo, reparaciones y costas, (ser. C) No. 111, 95-6 (Ago. 31, 2004).

66 Kimel v. Argentina, Sentencia de fondo, reparaciones y costas, (ser. C) No. 177, 58 (mayo 2, 2008). La cuarta condición ha sido posteriormente reafirmada por la jurisprudencia de la
} 
Bajo el Pacto, los requisitos son bastante similares. En términos generales, una restricción debe estar prescrita en la ley, debe estar orientada a cumplir uno o más objetivos permitidos en el texto del tratado y debe ser necesaria y proporcional para alcanzar tal finalidad. El Comité ha construido esta estructura doctrinal, a través de distintas Observaciones y mediante las Observaciones generales. El primer requisito exige que las restricciones estén "previstas" por la ley ${ }^{67}$. El Comité ha especificado este presupuesto, el 2011, en su Observación General No. 34, en lo que respecta a la libertad de expresión ${ }^{68}$. Ahí se lee que "para ser calificada de 'ley', la norma debe estar formulada con precisión suficiente para que una persona pueda regular su comportamiento de conformidad con ella, y hacerse accesible al público" ${ }^{69}$. Precisión en la restricción y accesibilidad de la norma son, por tanto, los dos componente materiales del primer requisito. Así, en este texto, el Comité recoge y sistematiza su jurisprudencia previa, sobre la materia ${ }^{70}$. En relación al segundo presupuesto, el Comité emplea distintas expresiones tales como "fines permisibles" 71 o "razones legítimas" 72 . Al respecto, ha señalado que tales fines o razones deben ser interpretados de manera "estricta", lo que significa que un derecho solo puede ser restringido en función de uno de los fines legítimos que, en su articulado, el Pacto haya previsto para ese derecho, prohibiendo aplicaciones analógicas de los fines admitidos ${ }^{73}$. Por ejemplo, la libertad de manifestar su religión o creencias puede ser restringida en función de la protección de la salud o la moral públicas, pero no por consideraciones de seguridad nacional ${ }^{74}$. En tercer término, las restricciones deben satisfacer "pruebas estrictas de necesidad y proporcionalidad" 75 . Ambos tests constituyen un examen de corrección de medidas estatales, que atiende a los casos concretos y que recurre a la identificación de condiciones de aplicación de los distintos enunciados normativos bajo el Pacto. Necesidad y proporcionalidad son estándares sensibles a los hechos de cada caso.

Corte. Véase Usón Ramírez v. Venezuela, Sentencia de excepciones preliminares, fondo, reparaciones y costas (ser. C) No. 207, 49 (Nov. 20, 2009).

67 La expresión "previstas" por la ley se encuentra en los artículos 12, 21 y 22. El Pacto utiliza otras expresiones para designar el mismo requisito: "prescrita" por la ley (artículo 18); "expresamente fijadas por la ley" (artículo 19) y "conforme" a la ley (artículo 13). El Comité trata todas estas expresiones como normativamente equivalentes.

68 Observación General No. 34, cit.

69 Id., 25.

70 Véase también Pinkney v. Canadá, Comm. No. 27/1978, Oct. 29, 1981, 34.

71 Observación General No. 27. La Libertad de Circulación (Artículo 12), CCPR/C/21/Rev.1/ Add.9, Nov. 2, 1999, 14.

72 Observación General No. 34, cit., 28.

73 Véase, mutatis mutandi, Observación General No. 22. Libertad de Pensamiento, de Conciencia $y$ de Religión (Artículo 18), CCPR/C/21/Rev.1/Add.4, Jul. 30, 1993, 8.

74 Artículo 18(3) del Pacto.

75 Observación General No. 34, cit., 22. En el mismo sentido, Observación General No. 27, cit., 11, 14 y 16; Observación General No. 22, cit., 8. 
Las Observaciones que aplican estos tests usualmente articulan diferentes grados de deferencia internacional.

Las siguientes secciones examinan cómo el Comité ha aplicado los estándares de necesidad y proporcionalidad, bajo el Pacto, y si acaso existe algún margen para la deferencia internacional en la restricción nacional de derechos. Las Observaciones del Comité no pueden, sin embargo, ser consideradas precedentes -en el sentido técnico de la palabra- aunque dicho órgano internacional, con el objeto de apoyar la interpretación autoritativa del Pacto, suele citar sus Observaciones previas, tal como un tribunal internacional. La reconstrucción de las Observaciones en clave de precedente pueden permitir construir una mejor comprensión de los nichos de discreción nacional, pese a que no exista un concepto específico como el MDA.

\section{2) SEGURIDAD NACIONAL Y RESTRICCIÓN DE DERECHOS}

Una de las mejores materias para indagar sobre discreción nacional y supervisión internacional bajo el Pacto, se encuentra en las Observaciones en los que los Estados han invocado la finalidad de seguridad nacional para efectos de restringir un derecho. Sin embargo, cabe advertir desde un inicio, el Comité suele resolver sobre una base extremadamente asistemática y casuística.

Las Observaciones que analizan problemas de seguridad nacional ilustran cómo el Comité intenta construir un estándar propio en la materia. Un par de ejemplos pueden ilustrar este punto. Para comenzar, debe citarse el caso de V.M.R.B. v. Canadá, en él un periodista fue expulsado a El Salvador, previa decisión de las autoridades inmigratorias que rechazaron una petición de asilo ${ }^{76}$. Canadá argumentó que existían razones de seguridad nacional que permitían justificar la medida, pero el autor de la comunicación replicó que tales consideraciones lo "castigaban" por sus opiniones políticas ${ }^{77}$. El Comité decidió que el caso era inadmisible. Entre las razones que dio, el organismo sostuvo que "el Estado Parte ha invocado razones de seguridad nacional en relación al procedimiento para haberlo deportado. No le corresponde a este Comité supervisar la evaluación de seguridad que sobre un extranjero hace un Estado soberano [...]"78. En el contexto de la comunicación, uno podría considerar tal afirmación como un exceso retórico, ya que el Comité no reniega la supervisión de restricciones nacional a los derechos sobre la base de consideraciones de seguridad nacional. Ello fue explícitamente tratado en Borzov v. Estonia,

76

V.M.R.B. v. Canadá, Comm. No. 236/1987, Jul. 18, 1988.

Id., 4.4 y 5.4 .

Id., 6.3, énfasis agregado. 
donde el Comité debía resolver si era razonable y objetiva la denegación de otorgar ciudadanía a un residente permanente - un ex uniformado de la Unión Soviética-, conforme al artículo $26^{79}$ del Pacto ${ }^{80}$. Estonia argumentó sobre la base de la decisión en V.M.R.B., con el objeto de defender la apreciación estatal sobre lo que constituye una amenaza para la seguridad nacional ${ }^{81}$. El Comité, no obstante, rechazó aplicar el mismo criterio en forma exegética y literalista. Al enfrentar la pregunta jurídica sobre discreción, la Observación enfatizó "que la invocación de la seguridad nacional por parte del Estado no remueve en su totalidad, e ipso facto, una cuestión sometida al escrutinio del Comité"82. Más aún, redefinió el nivel de discrecionalidad nacional para estos asuntos:

"Mientras el Comité no puede dejarlo a la discrecionalidad sin límites de un Estado Parte en relación a razones de seguridad nacional que pudieren existir en un caso individual, reconoce que tiene un rol propio en la revisión de la existencia y relevancia de tales consideraciones que dependerá de las circunstancias del caso y el precepto pertinente del Pacto. Aunque los artículos 19, 21 y 22 del Pacto establece un criterio de necesidad respecto de restricciones basadas en la seguridad nacional, el criterio aplicable bajo el artículo 26 es más general en naturaleza, requiriendo una justificación objetiva y razonable para las distinciones en base a características individuales enumeradas en el artículo 26, incluyendo 'otra condición social'. El Comité acepta que consideraciones relacionadas a la seguridad nacional pueden servir a una finalidad legítima en el ejercicio soberano de un Estado Parte al otorgar ciudadanía a una persona, al menos cuando un Estado recientemente independiente invoca preocupaciones de seguridad nacional en conexión con su status pasado" 83 .

El argumento tiene implicancias relevantes para nuestro estudio. En primer término, reafirma el rol del Comité en la supervisión de las razones de los Estados Parte brindadas para la restricción de derechos. Segundo, establece que estas materias deben ser examinadas según los antecedentes de cada caso y en relación con el precepto del Pacto que co-

\footnotetext{
79 "Artículo 26.

Todas las personas son iguales ante la ley y tienen derecho sin discriminación a igual protección de la ley. A este respecto, la ley prohibirá toda discriminación y garantizará a todas las personas protección igual y efectiva contra cualquier discriminación por motivos de raza, color, sexo, idioma, religión, opiniones políticas o de cualquier índole, origen nacional o social, posición económica, nacimiento o cualquier otra condición social.”

80 Borzov v. Estonia, Comm. No. 1136/2002, Ago. 25, 2008.

Id., 4.6.

Id., 7.3 .

Id., énfasis agregado.
} 
rresponda. Por tanto, dependiendo de los hechos de cada caso, el Comité puede decidir si la restricción -en este caso, una discriminación potencial del Estado- tiene una "justificación razonable y objetiva" y una finalidad legítima para distinciones basadas en características personales del sujeto, conforme al artículo 26 del Pacto. El estándar de "justificación razonable y objetiva" pareciera ser, según lo afirmado por el Comité, distinto a la cláusula de necesidad que se establece en los artículos 19, 21 y 22 del Pacto. Sin embargo, el Comité no desarrolla la diferenciación entre ambos estándares de supervisión internacional. En Borzov, el Comité prestó especial atención a los siguientes factores: el entrenamiento militar del autor de la comunicación, su ex rango militar y su trayectoria en las Fuerzas Armadas de la Unión Soviética. Al examinarlas en conexión con las razones de seguridad nacional, concluyó que no había existido una discriminación contraria al artículo $26^{84}$. La decisión del Comité concluye con una afirmación particularmente relevante, respecto a la discreción en materias de seguridad nacional. Este sostuvo que "ni el Pacto ni el Derecho Internacional en general explicitan un criterio especifico para el otorgamiento de la ciudadanía mediante naturalización, y el autor sí tenían un derecho a que la denegación de su postulación de nacionalización fuese revisada por los tribunales del Estado parte" 85 . La nacionalización, según el Comité, constituye una materia en la que los Estados Parte gozan de cierta latitud, al no haberse establecido previamente -en el Pacto o el Derecho Internacional- criterios específicos para su otorgamiento. Tal deferencia, sin embargo, no anula por completo el escrutinio internacional, tal como lo afirmó en este caso.

En otra comunicación, el Comité tuvo la oportunidad de aplicar el escrutinio internacional bajo el estándar de "necesidad" y ya no de "justificación objetiva y razonable", en materia de seguridad nacional. En Kim v. República de Corea, el Comité tuvo que revisar la compatibilidad de la Ley de Seguridad Nacional de Corea con la libertad de expresión establecida en el artículo 19 del Pacto ${ }^{86}$. El autor de la comunicación distribuyó documentos que clamaban por la reunificación con Corea del Norte y criticaba la posición del gobierno sobre la materia. Luego de un evento público en el que distribuyo los textos, fue detenido y condenado a tres años de presidio y uno de suspensión para elección en cargos públicos, bajo la Ley de Seguridad Nacional ${ }^{87}$. El Comité comenzó su razonamiento fijando los tres presupuestos válidos que son "copulativos" para restringir la libertad de expresión conforme al Pacto: la limitación "debe estar prevista en la ley, debe dirigirse a uno de las finalidades establecidas en los pará-

Id., 7.4.

Id., énfasis agregado.

Kim v. República de Corea, Comm. No. 574/1994, Ene. 4, 1999.

Id., 2.1-2.2. 
grafos 3(a) y (b) del artículo 19 (respeto a los derechos o a la reputación de los demás; protección de la seguridad nacional, el orden público o la salud o la moral públicas) y debe ser necesaria para alcanzar una finalidad legítima" 88 .

Las primeras dos condiciones fueron fácilmente satisfechas en este caso particular y el Comité tenía que decidir si la restricción era necesaria, bajo los términos del artículo 19(3) del Pacto ${ }^{89}$. En este último presupuesto, la Observación declara explícitamente "la necesidad de un escrutinio cuidadoso por el Comité, lo que es enfatizado por los términos amplios e inespecíficos bajo los cuales está formulado el delito en la Ley de Seguridad Nacional" 90 . Sobre el requisito de necesidad, el Comité debía evaluar si la distribución de los textos "crearon un riesgo para la seguridad nacional", evaluar "la naturaleza y extensión de ese riesgo" y si su contenido "tuvo un efecto adicional en la audiencia o lectores que generase una amenaza a la seguridad pública" ${ }^{91}$. Sobre estas condiciones, decidió que el Estado no había justificado debidamente la restricción de la libertad de expresión del autor.

El Comité ha ido refinando su propio estándar de escrutinio en materia de seguridad nacional. La inicial deferencia amplia aplicada en V.M.R.B. v. Canadá cambió en Borzov, donde se reivindica la competencia del Comité para supervisar el cumplimiento de las obligaciones del Pacto, negando una "discreción sin límites." Por tanto, no hay una carte blanche para los Estados Parte, incluso en áreas tan sensibles como la seguridad nacional. Los derechos pueden ser restringidos válidamente bajo el Pacto pero sujetos a la revisión internacional por parte del Comité. Los siguientes apartados analizan cómo se desarrollan estándares para tal fin.

\section{3) LIBERTAD DE EXPRESIÓN}

Uno de los grupos de casos más relevantes en materia de discreción nacional, dice relación con las restricciones a la libertad de expresión. El texto ya abordó algunas de ellas más arriba -a propósito de la seguridad nacional- pero ahora nos abocaremos específicamente a discernir otras hipótesis de restricción a dicho derecho. Tal como se apuntó en la sección anterior, la libertad de expresión admite restricciones que han sido prescritas por la ley, que persiguen una finalidad legítima establecida en el artículo 19(3) y que sea necesaria para alcanzar uno o más de estos fines ${ }^{92}$.

\footnotetext{
88 Id., 12.2. Tal como revisamos en supra 2.1, este test tripartito fue luego asumido como doctrina general incorporado en la Observación General No. 34.

Cfr. supra 2.1. Véase también Observación General No. 34, cit.
} 
Los casos de libertad de expresión pueden ser divididos en dos grupos, en relación a la intensidad del escrutinio internacional. El primer grupo engloba los casos de protección del discurso político. Aquí, el Comité tiende a intensificar su estándar de revisión internacional y solo permite, siquiera, una reducida deferencia a las autoridades nacionales. El segundo grupo es distinto y posee un estándar más laxo de supervisión internacional de las restricciones. Casos de discurso del odio (hate speech) pueden ser agrupados aquí. Lo mismo pasa con cuestiones moralmente controversiales, tal como discutimos a propósito del caso Hertzberg, aunque luego el Comité cambiase de criterio en Fedotova ${ }^{93}$. En esta parte del texto se proveen de ejemplos en ambos grupos de casos, con el objeto de explicar las diferencias en términos de supervisión internacional.

\subsection{1) Discurso político}

Un buen ejemplo de este primer grupo de casos se encuentra en Marqués de Morais v. Angola. El Comité tenía que resolver si la condena de un periodista por haber criticado al Jefe de Estado en Angola, se encontraba conforme a lo dispuesto al artículo 19 del Pacto, entre otras disposiciones. El Comité precisó que la libertad de expresión "incluye el derecho de los individuos a criticar o evaluar abierta y públicamente sus Gobiernos, sin el miedo de interferencia o castigo"94. A partir de tal premisa, sostuvo que el requisito de "necesidad" del artículo 19(3) "implica un elemento de proporcionalidad" y, por tanto, "el alcance de la restricción impuesta a la libertad de expresión debe ser proporcional al valor que la restricción busca proteger" 95 . La Observación prosigue precisando el examen de proporcionalidad en casos de discursos políticos. Para ello atiende al rol "primordial" que cumple la libertad de expresión en las sociedades democráticas ${ }^{96}$. El autor de la comunicación fue condenado

Véase supra 1.2.

Marqués de Morais v. Angola, Comm. No. 1128/2002, Mar. 29, 2005, 6.7.

Id., 6.8.

El Comité citó la Observación General No. 25: "La libre comunicación de información e ideas acerca de las cuestiones públicas y políticas entre los ciudadanos, los candidatos y los representantes elegidos es indispensable para garantizar el pleno ejercicio de los derechos amparados por el artículo 25. Ello comporta la existencia de una prensa y otros medios de comunicación libres capaces de comentar cuestiones públicas sin censura ni limitaciones, así como de informar a la opinión pública. Requiere el pleno disfrute y respeto de los derechos garantizados en los artículos 19, 21 y 22 del Pacto, incluida la libertad de participar en actividades políticas individualmente o a través de partidos políticos y otras organizaciones, la libertad de debatir los asuntos públicos, de realizar manifestaciones y reuniones pacíficas, de criticar o de oponerse al gobierno, de publicar material político, de hacer campaña electoral y de hacer propaganda política." Observación General No. 25. La Participación en los Asuntos Públicos y el Derecho a Voto (Artículo 25), CCPR/C/21/Rev.1/Add.7, Jul. 12, 1996, 25. Esta dimensión democrática es repetida en la Observación General No. 34, cit., 20. 
a seis meses de prisión -siendo suspendidos en su aplicación por el plazo de 5 años- y se ordenó pagar una elevada suma de dinero, por un lado, como indemnización de perjuicios y, por el otro, como costas judiciales. Sobre la base de la condena efectiva, el Comité estimó que tal restricción era innecesaria: "la severidad de las sanciones impuestas sobre el autor no pueden ser consideradas como una medida proporcional para proteger el orden público o el honor y la reputación del Presidente, una figura que, en cuanto tal, está sujeta a crítica y oposición"97. En conclusión, el Comité encontró una violación al artículo 19 del Pacto.

En materias de libertad de expresión, el Comité ha señalado que las restricciones deben satisfacer un "estricto test de justificación.” Al parecer, dicha expresión fue usada, por primera vez, en Park v. República de Co$r e a^{98}$. La cuestión jurídica que debía resolverse en Park era si el Acta de Seguridad Nacional del Estado era compatible con los preceptos del Pacto sobre libertad de expresión. El autor de la comunicación fue condenado por haber participado en un grupo donde se mantenían discusiones sobre la paz y la reunificación. El Comité, tras lo decidido en $\mathrm{Kim}^{99}$, consideró que las restricciones a la libertad de expresión deben satisfacer el "estricto test de justificación." En los hechos del caso, el Comité "notó que el Estado Parte ha invocado la seguridad nacional, al referirse a la situación general del país y la amenaza representada por "comunistas norcoreanos" 100. Pero la mera invocación de un objetivo legítimo y una referencia genérica al contexto no se consideró suficiente para justificar la medida. El Comité destacó que Corea "falló en especificar la naturaleza precisa de la amenaza"101. La doctrina ha agregado que el Estado debe también demostrar "cómo la limitación [del derecho] consigue disipar tal amenaza"102. El Comité estimó que una referencia genérica al contexto político e internacional del Estado Parte era insuficiente para justificar las restricciones impuestas y, por tanto, falló en satisfacer el test descrito, lo que generó la declaración de violación del Pacto.

Otros casos son decididos en forma similar. Las comunicaciones relacionadas con opiniones políticas y críticas a los gobiernos son severamente supervisadas y se emplea, en general, la referencia al "estricto test de justificación"103. Buenos ejemplos se pueden encontrar en las comunicaciones seguidas contra Bielorrusia. En Velichkin v. Bielorrusia, se detuvo a un activista de derechos humanos por distribuir copias de la Declara-

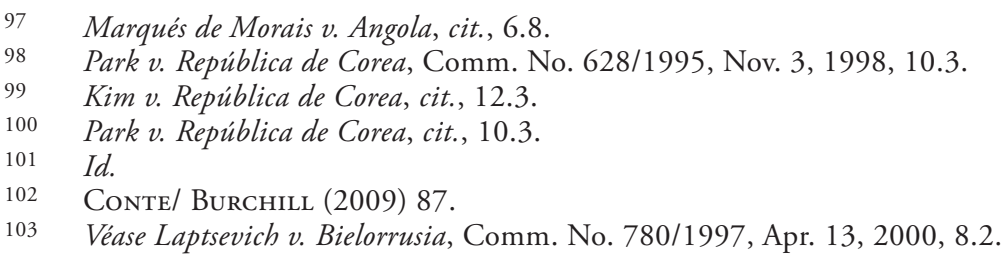


ción Universal de Derechos Humanos, para posteriormente ser multado con una importante suma de dinero ${ }^{104}$. De acuerdo a la Observación, el Estado falló en justificar la "naturaleza específica" de la amenaza al orden público y, consecuentemente, el Comité determinó que hubo una violación a la libertad de expresión contenida en el artículo 19 del Pacto ${ }^{105}$. En Korneenko y Milikenvich v. Bielorrusia, el Comité estimó que la incautación y destrucción de panfletos políticos era desproporcionada ${ }^{106}$. El Estado Parte solo arguyó que la medida restrictiva era lícita y conforme a la legislación nacional. Sin embargo, el Comité consideró que tales razones, por sí solas, no eran suficientes para justificar una restricción sobre la libertad de expresión.

Una revisión de estos casos emblemáticos demuestra que el Comité ejercita una supervisión atenta y cercana a las restricciones al discurso político, protegido por la libertad de expresión. Las Observaciones del Comité consideran que este derecho protege la crítica pública y la evaluación abierta de las autoridades oficiales. Más aún, aunque no se trata de un derecho absoluto, la discreción nacional debe satisfacer un "estricto test de justificación" a la hora de restringir el derecho del artículo 19 del Pacto. Ello importa que el Estado debe detallar la "naturaleza específica" de la amenaza a una de las finalidades legítimas del derecho antes citado y también demostrar cómo la restricción sirve el propósito de atacar la amenaza especificada.

\subsection{2) Otros tipos de discurso}

El Comité ha decidido otros casos que se refieren a los límites a la libertad de expresión. Para el objeto de este texto, será suficiente ilustrar cómo varían los estándares de escrutinio internacional en materia de discurso del odio (hate speech). En esta materia, cabe señalar que el Pacto establece una disposición especial. El artículo 20 establece que "[t]oda propaganda en favor de la guerra estará prohibida por la ley" y que "[t]oda apología del odio nacional, racial o religioso que constituya incitación a la discriminación, la hostilidad o la violencia estará prohibida por la ley" ${ }^{107}$. Este precepto establece una obligación positiva que obliga a los Estados a promulgar restricciones específicas sobre la libertad de expresión. Aunque los casos de discurso de odio podrían haber sido resueltas bajo el artículo 20 del Pacto, el Comité ha decidido revisarlos bajo el esquema de restricciones del artículo 19(3). A continuación, se desarrolla el impacto que

\footnotetext{
104 El equivalente a 20 salarios mínimos mensuales. Velichkin v. Bielorrussia, Comm. No. 1022/2001, Oct. 20, 2005, 7.2.

Id., 7.3 .

106 Korneenko y Milikenvich v. Bielorrusia, Comm. No. 1553/2007, Mar. 20, 2009, 8.3.

107 Artículo 20 del Pacto.
} 
tiene el artículo 20 en la discreción de las autoridades estatales, junto al examen de los casos en que el Comité ha adoptado un enfoque más deferente en relación con los Estados Partes.

El Pacto, en su artículo 20, tiene dos cláusulas específicas de limitación de la libertad de expresión en materia de apología a la guerra y la incitación al odio en los casos contemplados. El Comité no ha resuelto, hasta el momento, una comunicación en base a este precepto. Sin embargo, en una de sus Observaciones Generales el Comité declaró que "tienen la obligación de adoptar las disposiciones legislativas necesarias para prohibir las actividades a que se refiere ese artículo" ${ }^{108}$. Al concretizar el mandato del artículo 20, el Comité ha definido una obligación positiva que recae sobre los Estados Parte, requiriendo promulgar o modificar la legislación nacional con el objetivo de implementar internamente las prohibiciones antes señaladas. Por ello, en términos de discreción nacional, la obligación impone una constricción en la esfera de actuación del Estado Parte, respecto de la tutela y regulación de la libertad de expresión. La Observación General, sin embargo, no ha detallado las modalidades específicas por las cuales se puede cumplir el mandato descrito. ¿QQué se entiende por "disposiciones legislativas necesarias"? ¿Debe ser criminalizado el discurso del odio y la apología de la guerra? Si tal es el caso, ¿debe castigarse con penas de privación de libertad? ¿O bastaría establecer sanciones pecuniarias o, en ciertos casos de discurso del odio, mecanismos de reparación civil para las víctimas? La obligación positiva nos lleva, entonces, a un segundo nivel de análisis respecto de la discreción nacional. Puesto que la especificación de la modalidad de cumplimiento está reservada a los Estados Parte, sus autoridades pueden definir las reglas particulares que operativizan el mandato del artículo 20. En general, la definición concreta del mandato pareciera estar bajo la discreción de los Estados Parte, siempre y cuando se cumpla con la prohibición que debe establecerse. Si es así, entonces el Estado ha cumplido con el deber positivo que se deriva del Pacto.

Pese a la prohibición explícita establecida en el artículo 20, los casos que podrían haber sido subsumidos en tal disposición han sido resueltos bajo el esquema general de corrección de los límites a la libertad de expresión, del artículo 19. En Faurisson v. Francia, un ciudadano francés fue condenado por negar la existencia del Holocausto ${ }^{109}$. El autor profirió dos afirmación que fueron la base para la condena. Primero, "tengo excelentes razones para no creer en la política de exterminio de judíos o en las cámara de gases mágicas." Segundo, "me gustaría ver al 100 por ciento de los ciudadanos franceses que se den cuenta que el mito de las cámaras de

108 Observación General No. 11. Artículo 20. HRI/GEN/1/Rev.9 (Vol.I), Jul. 29, 1983, 1.

109 Faurisson v. Francia, Comm. No. 550/1993, Nov. 8, 1996. 
gases es una fabricación deshonesta"110. La legislación francesa disponía como delito, sancionado con multa, "impugnar la existencia de la categoría de crímenes contra la humanidad, definidos en la Carta de Londres de 8 de agosto de 1945"111. El Comité asumió gran parte de los argumentos presentados por el Estado Parte y estimó que la restricción era necesaria para "servir en la lucha contra el racismo y el antisemitismo"112. En este caso, el Comité estimó que no había una violación del artículo 19. La decisión básicamente brindó deferencia al Estado para que este garantice que la comunidad judía pueda vivir "libre del miedo de una atmósfera antisemítica"113. Cabe señalar que tres miembros del Comité concurrieron al voto de mayoría y consideraron que, en el contexto de Francia, las expresiones de Faurisson constituyeron una incitación al antisemitismo. Por tanto, según estos miembros del Comité, la legislación francesa estaba en concordancia con el artículo 20 del Pacto y esta era la razón de por qué debía ser rechazada la comunicación en el fondo ${ }^{114}$.

El segundo caso se relaciona con el despido de un profesor por expresiones antisemíticas. En Ross v. Canadá, el Comité se abocó a la cuestión jurídica en forma similar a lo resuelto en Faurisson ${ }^{115}$. Así, determinó que la medida adoptada por el Estado Parte buscaba proteger la finalidad legítima de proteger los derechos y la reputación de terceros. Específicamente, el Comité sostuvo que las afirmación de Ross "eran discriminatorias en contra de personas de religión judía” y concluyó que la restricción de la libertad de expresión era compatible para proteger sus derechos y "el derecho a tener una educación en un sistema escolar público que sea libre de prejuicios, estereotipos e intolerancia"116. Al considerar las razones para rechazar la comunicación, el Comité recalcó la “influencia” que los profesores de escuelas ejercen sobre sus estudiantes. Esta influencia, tal como señala la Observación, "puede justificar restricciones con el objeto de asegurar que no se le dé legitimidad a la expresión de ideas que son discriminatorias, por parte del sistema escolar"117. La decisión concluyó que no existió violación del artículo 19 del Pacto.

Estos dos ejemplos ilustran cómo el Comité distingue entre tipos de discursos amparados por la libertad de expresión, a efectos de la revisión y escrutinio internacional. Las decisiones, aunque no siempre de manera

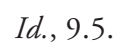

Id., opinión concurrente de los Comisionados Elizabeth Evatt y David Kertzmer, cofirmada por Eckart Klei, 5-6.

115 Ross v. Canadá, Comm. No. 736/1997, Oct. 18, 2000, 11.2 (examinando los requisitos del artículo 19(3) para restringir la libertad de expresión).

116 Id., 11.5.

$117 \quad$ Id., 11.6. 
explícita, brindan deferencia a las razones de los Estados y las autoridades nacionales con el objeto de proteger los derechos e intereses de terceros.

\section{4.) LIBERTAD RELIGIOSA}

Otro set de casos en los que el Comité brinda deferencia internacional a las autoridades estatales se puede encontrar en las controversias sobre libertad religiosa. El artículo 18 del Pacto establece la libertad de pensamiento, de conciencia y de religión ${ }^{118}$. De acuerdo al Comité, el Pacto "[n]o permite ningún tipo de limitación de la libertad de pensamiento y de conciencia o de la libertad de tener la religión o las creencias de la propia elección"119. En la estructura del artículo 18, solo la "libertad de manifestar la propia religión o las propias creencias" puede estar sujeta a las limitaciones prescritas bajo el apartado 3 de dicho precepto ${ }^{120}$. Por lo tanto, para comprender los estándares de deferencia es necesario revisar los casos en que los Estados Parte han argumentado que la libertad en cuestión fue válidamente restringido bajo el Pacto.

Uno de los casos más interesantes en materia de deferencia y esta libertad, corresponde a la prohibición de drogas y estupefacientes ilícitos en relación con la práctica de ritos o ceremonias religiosas. El primer caso en que se abordó esto fue declarado inadmisible, pero es relevante tener presente los antecedentes que evaluó el Comité. Los autores de la comunicación en M.A.B., W.A.T. y J.-A.Y.T. v. Canadá eran miembros de la "Asamblea de la Iglesia del Universo" y argumentaron que la veneración y el consumo de cannabis sativa era parte de sus ritos religiosos y constituía un "sacramento"121. En dicho Estado, la legislación penal vigente criminalizaba el uso y distribución de cannabis. El Comité se negó a entrar a conocer el mérito del asunto porque estimó que los hechos de la comunicación no constituían un problema jurídico bajo el Pacto. En particular, el Comité sostuvo que "una creencia que consiste primaria o exclusivamente en la veneración y distribución de un narcótico no puede ser subsumido bajo el alcance del artículo 18 del Pacto [...]"122. No hay, pues, análisis del fondo o si la restricción perseguía alguna finalidad legítima. La decisión de inadmisibilidad dejó la puerta abierta para comunicaciones de leyes antidrogas en donde el rito o la práctica religiosa no consistiere "primaria o exclusivamente" en el consumo de narcóticos ilegales. Así, un nuevo caso llegó al Comité. En Prince v. Sudáfrica, el Comité tuvo que

Supra nota 6.

Observación General No. 22, cit., 3.

Malakhovsky \& Pikul v. Bielorrusia, Comm. No. 1207/2003, Jul. 26, 2005, 7.2, énfasis en el original.

121 M.A.B., W.A.T. \&J.-A.Y.T. v. Canadá, Comm. No. 570/1993, Abr. 8, 1994, 2.1.

$122 I d ., 4.2$. 
decidir si la criminalización del uso de la cannabis sativa para las prácticas religiosas de rastafaris, era compatible con la libertad de manifestar la propia religión ${ }^{123}$. El Estado argumentó, en primer lugar, que el caso debía ser declarado inadmisible teniendo como precedente lo decidido en M.A.B., W.A.T. y J.-A.Y.T. Sin embargo, el Comité sostuvo que este caso puede ser distinguido del anterior ya que el "Rastafarianismo es una religión bajo el sentido del artículo 18" y no se centra "primaria o exclusivamente en la veneración y distribución de un narcótico" 124 . A continuación, la decisión pasa a examinar los méritos. Aquí, el Comité admite que la penalización del uso de cannabis constituye una limitación del derecho establecido en el artículo $18^{125}$. No obstante, al revisar el requisito de necesidad, el Comité descansó considerablemente en la argumentación del Estado Parte. Expresamente, sostuvo que

"la conclusión del Estado Parte que la ley en cuestionamiento fue diseñada para proteger la seguridad pública, el orden, la salud, la moral o los derechos y libertades fundamentales de terceros, en base a los dañinos efectos de la cannabis, y que una excepción admitiendo un sistema de importación, transporte y distribución a los rastafaris puede constituir una amenaza al público en general, si alguna parte de la cannabis entrara en circulación general. Bajo estas circunstancias, el Comité no puede concluir que la prohibición de la posesión y uso de drogas, sin excepciones para grupos religiosos específicos, no sea proporcional y necesaria para alcanzar este objetivo"126.

El argumento del Comité, sin emplear una noción clara de deferencia, básicamente articula una discrecionalidad estatal para perseguir los fines legítimos establecidos en el artículo 18(3) del Pacto. El Comité brinda considerable deferencia en dos cuestiones centrales de la comunicación: uno, para la determinación de los "efectos dañinos" de la posesión y uso de la cannabis para el público en general y, dos, para la determinación de los medios nacionales que puedan lograr alcanzar las finalidades legítimas que justifican las restricciones al derecho. Así, a diferencia de los casos revisados sobre libertad de expresión política -donde la naturaleza de la amenaza era cuidadosamente examinada-, la aproximación del Comité es considerablemente más laxa. La decisión permite que sean los Estados quienes determinen si estiman necesario o no despenalizar esta droga o establecer excepciones especiales para grupos religiosos particulares. Ello no está ordenado por el Pacto y queda en la esfera de discrecionalidad de

Prince v. Sudáfrica, Comm. No. 1474/2006, Oct. 31, 2007.

Id., 6.5 .

Id., 7.3 .

Id. 
los Estados. En Prince, Sudáfrica argumentó a favor de una prohibición absoluta en el uso de cannabis, aplicable a cualquier habitante del país. Asimismo, defendió que tal medida legislativa era la única solución operativa para precaver el tráfico ilegal de la droga ${ }^{127}$. El Comité consideró que la negativa estatal a introducir una excepción a favor de los rastafaris no era desproporcionada para la protección de los objetivos citados por Sudáfrica ${ }^{128}$.

Un criterio deferencial similar puede encontrarse en causas de libertad religiosa en las que se contraponían intereses de seguridad y prevención de riesgos. En Malakhovsky y Pikul v. Bielorrusia ${ }^{129}$, los autores de la comunicación eran miembros de la comunidad Krishna y trataron sin éxito de registrar una asociación religiosa. Según la comunicación, las medidas administrativas adoptadas por el Estado habrían violado su libertad de manifestar las propias creencias, ya que el registro era necesario para divulgar y exhibir legalmente los símbolos religiosos. Bielorrusia negó el registro de la asociación por dos razones. Primero, por carecer de un domicilio legal adecuado; segundo, y más importante, porque el lugar de culto "no cumplía con los requisitos del Código de Vivienda, ya que se habían identificado varias violaciones de seguridad en materia sanitaria y de prevención de incendios"130. El Comité aceptó rápidamente este último grupo de razones y sostuvo que los estándares de salud y seguridad públicas constituyen "una limitación necesaria para la seguridad pública y son proporcionales a esta necesidad" 131 . El requisito del domicilio legal, por otro lado, fue considerado como desproporcionado, ya que el Estado había fallado en justificar cómo dicha exigencia era necesaria para alcanzar alguna de las finalidades legítimas del artículo 18(3) del Pacto ${ }^{132}$. El Comité distingue entre los distintos requisitos administrativos para efectuar su examen de validez de las restricciones del derecho. Condiciones básicas de seguridad de terceros es un set de razones válidas para restringir la libertad de manifestación de las propias creencias.

Por último, existe un ámbito en donde el Comité ha aplicado un test de proporcionalidad con mayor rigurosidad. En Singh v. Francia, tuvo que afrontar el siguiente asunto: una regulación que ordenaba que las personas apareciesen con la cabeza descubierta para fotografías de identificación en permisos de residencia fue cuestionada porque producía el efecto de prohibir el uso de un turbante Sikh, violando así la libertad

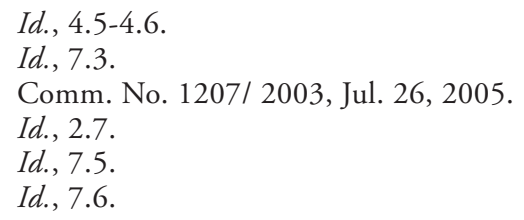


religiosa ${ }^{133}$. El Comité recordó que, tal como lo había declarado en la Observación General No. 22, que la libertad religiosa comprende el derecho a vestir prendas religiosas distintivas y concluyó que Francia no había justificado la necesidad y proporcionalidad de la medida para proteger el orden y la seguridad pública ${ }^{134}$. Este caso muestra una mayor intensidad en el escrutinio judicial que restringe severamente la discrecionalidad de las autoridades nacionales. El Comité parece haber confirmado su línea interpretativa en materia de libertad religiosa ${ }^{135}$ y tiende a aplicar un estándar más "universal" al examinar estas medidas restrictivas del derecho y su proporcionalidad. Por lo tanto, la protección de la libertad religiosa se hace con independencia de la práctica de los Estados Parte del Pacto o de su consenso moral sobre el punto.

En claro contraste, el Tribunal Europeo de Derechos Humanos ha utilizado la doctrina del MDA en casos similares, asegurando una latitud a los órganos estatales para la restricción y limitación de la libertad religiosa en relación con determinadas vestimentas. El Tribunal ha fundado sus decisiones en esta doctrina, especialmente cuando no existe consenso regional entre los Estados europeos. Los casos referidos a la exhibición de símbolos religiosos en escuelas públicas ${ }^{136}$ o el uso de velo islámico en lugares públicos ${ }^{137}$ son dos ejemplos nítidos en materia de MDA como doctrina de deferencia. En relación con la restricción al uso de turbantes Sikh, el Tribunal Europeo solo se ha pronunciado declarando inadmisible un caso ${ }^{138}$, pero aún no falla el fondo del asunto.

\section{5) NO DISCRIMINACIÓN}

Igualdad y no discriminación son dos principios centrales en la estructura del Pacto. Como parte de las obligaciones generales del tratado, el artículo 2(1) establece que los Estados Parte deben respetar y garantizar los derechos del Pacto "sin distinción alguna de raza, color, sexo, idioma, religión, opinión política o de otra índole, origen nacional o social, posición económica, nacimiento o cualquier otra condición social”. De igual forma, el artículo 3 hace explícita la regla de igualdad entre hombres y mujeres para el ejercicio y goce de los derechos del Pacto. Adicionalmente, el artículo 26 establece el derecho de igualdad ante la ley y la prohibición de discriminación.

\footnotetext{
133 Singh v. Francia, Comm. No. 1876/2000, Jul. 22, 2011.

134 Id., 8.4 .

135 Véase Hudoyberganova v. Uzbekistán, Comm. No. 931/2000, Ene. 18, 2005.

136 Lautsi v. Italia, App. No. 30814/06, Mar. 18, 2011.

137 Sahin v. Turquia, App. No. 44774/98, Nov. 10, 2005.

138 Shingara Mann Singh v. Francia, App. No. 24479/09, Nov. 13, 2011.
} 
El Comité ha declarado que el artículo 26 constituye un derecho "autónomo". En otras palabras, tal precepto no "reitera" la prohibición de discriminación establecida en el artículo 2(1) del Pacto ${ }^{139}$. Esta interpretación tiene un impacto en el grado de discreción que gozan las autoridades nacionales bajo el artículo 26. La protección de tal disposición se aplica a cualquier derecho que, si bien no está garantizado en el Pacto, ha sido otorgado o reconocido por el Estado Parte a los individuos. Al estimar que el derecho del artículo 26 es un derecho autónomo, la protección de no discriminación que brinda el Pacto se ve ampliada a otros derechos. Así, por ejemplo, la extensión de protección llega hasta el derecho a la propiedad privada. Tal como lo han seńalado Conte y Burchill, "si un Estado decide promulgar leyes que discriminan a favor de ciertas personas que pueden adquirir el dominio de bienes mientras que le niega este derecho a otros en base a su origen racial, esto violaría el artículo $26^{140}$. Esta extensión permite entender la discreción estatal, en lo referido a la igualdad ante la ley, de la siguiente forma. En un primer nivel, el Estado define si establece o asegura un derecho que no se encuentra en extenso catálogo de derechos humanos del Pacto. En este nivel, el Estado tiene una amplia discrecionalidad para determinar y asignar los derechos que estime pertinentes o relevantes ${ }^{141}$. El estándar de deferencia, sin embargo, se altera si el Estado asigna o define un determinado derecho. Pese a que dicho derecho pueda que no se encuentre en el Pacto, el Estado tiene la obligación internacional de proteger en términos igualitarios. En consecuencia, el escrutinio internacional se aboca a determinar si el Estado ha respetado la prohibición de discriminación del artículo 26 del Pacto. En este nivel, por ejemplo, encontramos casos que tratan sobre beneficios o prestaciones de seguridad social o de cesantía. El Comité ha decidido que el Pacto no "requiere que un Estado promulgue legislación para proveer seguridad social. Sin embargo, cuando dicha legislación es adoptada en un ejercicio de poder soberano del Estado, entonces la legislación debe satisfacer el artículo 26 del Pacto"142.

\footnotetext{
139 Observación General No. 18. No Discriminación, Nov. 10, 1989, 12.

140 Conte / Burchill (2009) 294.

141 Este análisis no considera otras obligaciones internacionales que un Estado pueda tener, por ejemplo, bajo un tratado diferente. Para ejemplificar esto, se puede describir la siguiente figura. Un Estado americano puede haber ratificado el Pacto y la Convención Americana de Derechos Humanos. Este último tratado reconoce el derecho a la propiedad privada. Si bien el Estado tendría discreción para reconocer el derecho a la propiedad privada bajo el Pacto, no aplica la misma conclusión respecto de la Convención Americana. En consecuencia, al considerar todos los factores, dicho Estado no tiene la discreción explicada en el texto, puesto que hay otra fuente de derecho internacional que obliga a proteger el derecho a la propiedad privada.

142 Broeks v. Holanda, Comm. No. 172/1984, Abr. 9, 1987, 12.4.
} 
El Comité también ha delineado el parámetro general de escrutinio internacional en materia de diferencias de trato. Tal como ha repetido en numerosas oportunidades, "no cualquier diferencia de trato constituirá discriminación, si los criterios para dicha diferenciación son razonables y objetivos y si el objeto es alcanzar una finalidad que es legitima bajo el Pacto"143. Conte y Burchill sostiene que mientras puede parecer que la Observación General No. 18 sugiere un "test tripartito de razonabilidad, objetividad y legitimidad de la finalidad, pareciera no ser el caso de lo que muestra la jurisprudencia del Comité"144. Razonabilidad y objetividad usualmente convergen en un mismo test o, en otras palabras, son examinadas por el Comité sin mayores distinciones ${ }^{145}$. Lo importante es que, sin perjuicio de los componentes del test de igualdad, existen algunos ejemplos que permiten identificar la forma en que el Comité autoriza distintos grados de discreción nacional en la diferenciación de trato que ha sido justificado bajo el Pacto. Al igual que en otros casos revisados más arriba, el Comité adopta una aproximación casuística en la comunicaciones sobre discriminación, lo que hace difícil definir los estándares de deferencia en detalle.

En el área del servicio civil, el Estado tiene usualmente discreción para el nombramiento y despido de funcionarios públicos. Primero, el Comité autoriza diferencias de trato cuando existen medidas de reparación a víctimas de violaciones a los derechos humanos. Un buen ejemplo se encuentra en Stalla Colsta v. Uruguay ${ }^{146}$. Tras el golpe militar y la recuperación de la democracia, el Estado aprobó una ley que ordenaba la reincorporación de empleados públicos despedidos bajo el régimen militar. El autor de la comunicación en contra de Uruguay argumentó que la legislación otorgaba "más derechos a los ex empleados públicos que al resto de los individuos", lo que generaría una violación de los artículos 2, 25(c) y 26 del Pacto ${ }^{147}$. El Comité estimó que la justificación de la

$143 \quad$ Id., 13, énfasis agregado.

144 Conte / Burchill (2009) 310.

145 Cfr., sin embargo, Oulajin y Kaiss v. Holanda, Comm. Nos. 406/1990 y 426/1990, Oct. 23, 1992. Los autores de la comunicación alegaban que el gobierno los discriminó al negarles un beneficio familiar, basado en un criterio de diferenciación entre "hijos propios" e "hijos adoptados". El Comité aplicó el test de objetividad y razonabilidad para revisar la diferencia de trato. Reconoció que la "distinción [entre hijos propios y adoptados] es objetiva" y decidió sobre la base del criterio de razonabilidad. Al tomar en consideración que ciertas limitaciones en la entrega de beneficios son inevitables, el Comité debía resolver lo siguiente: si la distinción legal y, en particular, el requisito que el padre adoptivo estuviese involucrado en la crianza del hiño adoptivo como presupuesto para conceder los beneficios, podía ser considerado razonable, de cara a la prohibición de discriminación del Pacto. El Comité aceptó la argumentación del Estado Parte y estimó que tal diferenciación no era incompatible con el artículo 26 del Pacto. Id., 7.4.

146 Stalla Colsta v. Uruguay, Comm. No. 198/1985, July 9, 1987.

$147 \quad I d ., 2.2$. 
legislación era suficiente y que no constituía una discriminación. La decisión subrayó la importancia de la reparación en este contexto y declaró que "los funcionarios públicos uruguayos despedidos por consideraciones ideológicas, políticas o sindicales fueron víctimas de violaciones al artículo 25 del Pacto y, en tal condición, tienen derecho a tener una reparación efectiva bajo el artículo 2(3)(a) del Pacto. La legislación debe ser vista como reparación. La implementación de la misma, por tanto, no puede ser considerada como incompatible con la referencia a las "condiciones generales de igualdad" del artículo 25(c) del Pacto. Tampoco puede ser considerada como una distinción injusta bajo el artículo 2(1) o como una discriminación prohibida bajo los términos del artículo 26 del Pacto"148. Las reparaciones en materia de violaciones a los derechos humanos, por tanto, pueden significar una diferenciación de trato no solo admitida por el Pacto sino que, en cierta forma, obligada por el mismo.

En segundo lugar, en Kall v. Polonia, el Comité declaró que no existió una discriminación en el despido de un ex empleado público, por las razones que a continuación se explican ${ }^{149}$. El autor de la comunicación era un ex miembro de la milicia cívica al interior del Ministerio del Interior. En el proceso de reestructuración, el Estado disolvió la policía secreta y la reemplazó con un nuevo órgano al interior de la burocracia. En dicho proceso, Kall fue despedido y reclamó que el Estado no lo había querido contratar de vuelta en razón de sus opiniones políticas. Polonia argumentó explícitamente que las decisiones "en materia de empleo se encuentran dentro de la discreción y apreciación del empleador" ${ }^{150}$. El Comité parece haber seguido implícitamente el argumento del Estado. Así, sostuvo que, bajo el artículo 25(c), los ciudadanos tienen el "derecho y la oportunidad, sin distinciones basadas en la raza, color, sexo, idioma, religión, opiniones políticas o de otra clase, nacionalidad u origen social, propiedad, nacimiento u otro estatus, y tener acceso al servicio civil sin restricciones irracionales y en condiciones generales de igualdad dentro del país" "151. Sin embargo, el razonamiento del Comité declaró que dicho derecho "no facultad a cada ciudadano a obtener un empleo garantizado en el servicio público"152. Respecto del fondo de la comunicación, el Comité debía decidir si la negativa a darle un puesto en la policía a Kall se debía por la cantidad de plazas disponibles o por sus opiniones políticas. Nuevamente, el razonamiento afirmó que el artículo 25(c) no asegura a un trabajo en la administración pública "sino que un acceso en condiciones generales de igualdad" y, en vista de los hechos del caso, el Comité

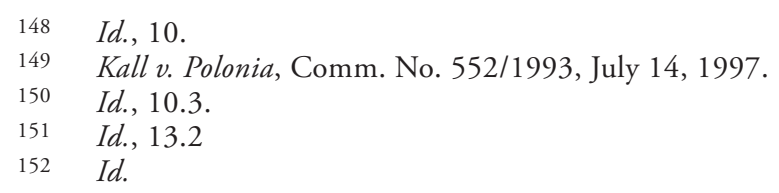


sostuvo que la información disponible no permitía fundar una violación del derecho ${ }^{153}$.

Otro ámbito en donde el Comité potencialmente podría generar una doctrina de deferencia se encuentra en los denominados problemas de “discriminación” positiva. En sus Observaciones Generales, el Comité ha apoyado ampliamente el uso de distintos mecanismos nacionales para "reducir o eliminar las condiciones que originan o facilitan que se perpetúe la discriminación prohibida por el Pacto"154. Ese conjunto de condiciones va desde exigir la realización de "actividades concretas para que las personas puedan disfrutar de sus derechos" 155 hasta un llamado explícito para adoptar "disposiciones especiales" (affirmative action) ${ }^{156}$. El Comité considera que los Estados Parte deben corregir las condiciones de discriminación mediante acciones positivas. La doctrina ha señalado que en esta materia nos encontraríamos en una "área de diferenciación justificada" 157. En la jurisprudencia del Comité, Jacobs v. Bélgica probaría este punto ${ }^{158}$. La comunicación trataba el problema jurídico sobre la compatibilidad de cuotas de género con la prohibición de discriminación establecida en el Pacto. Miembros del Alto Consejo de Justicia que no eran jueces, se seleccionaban bajo un criterio de cuota de género: se requería que hubiesen al menos cuatro postulantes de cada sexo entre los 11 miembros no jueces, lo que ascendía a poco más del tercio de los candidatos que eran electos en el cargo ${ }^{159}$. El Comité sintéticamente fraseó el dilema jurídico: si existía "alguna justificación válida para la distinción entre candidatos sobre la base de su sexo determinado"160. La primera cuestión que ocupó al Comité fue a la revisión de objeto de un cuota de género. El razonamiento se construye apoyándose fuertemente en los alegatos del Estado Parte sobre la materia: "dadas las responsabilidades de la judicatura, la promoción de una conciencia sobre los temas de género relevantes en relación con la aplicación del derecho, puede ser entendido como una exigencia para que dicha perspectiva sea incluida en el órgano involucrado en las designaciones de jueces" ${ }^{\prime 61}$. El requisito, por tanto, fue considerado como razonable

\section{Id., 13.3.}

154 Observación General No. 18, cit., 10.

155 Observación General No. 3. Aplicación del Pacto a Nivel Nacional (Artículo 2), July 29, 1981 (Sesión 13a, 1981), Compilation of General Comments and General Recommendations Adopted by Human Rights Treaty Bodies, HRI/GEN/1/Rev.9 (Vol. I), Mayo 27, $2008,1$.

Observación General No. 18, cit., 10; H Observación General No. 4. Derecho Igual de Hombres y Mujeres en el Goce de Todos los Derechos Civiles y Politicos (Articulo 3), July 30, 1981 (Thirteen Session, 1981), Compilation of General Comments and General Recommendations Adopted by Human Rights Treaty Bodies, HRI/GEN/1/Rev.9 (Vol. I), May 27, 2008, at 2.

157 Conte/Burchill (2009) 317.

158 Jacobs v. Bélgica, Comm. No. 943/2000, July 7, 2004.

$159 \quad I d ., 9.5$.

$160 \quad I d ., 9.3$.

161 Id., 9.4 . 
y objetivamente justificable. El Comité, luego, examinó si la cláusula de genero podía impactar desproporcionadamente respecto de los derechos de terceros. Así, el análisis de igualdad se complementa con el de proporcionalidad. El mecanismo de nombramientos con una cuota de género que estableció Bélgica fue considerado como proporcionado: "tal requisito no genera, en este caso, una desproporcionada restricción del derecho de acceso de los candidatos [a los cargos públicos]" y que "se preserva una razonable proporcionalidad" entre dicho acceso y "el objeto del requisito de género, cual es la promoción de la igualdad entre hombres y mujeres en órganos consultivos"162. En conclusión, la cuota fue respaldada por el Comité bajo las obligaciones del Pacto.

Finalmente, para efectos de esta investigación, hay dos decisiones más que deben ser revisadas. Se trata de ejemplos en que la forma de resolver la comunicación articula márgenes de discrecionalidad a los órganos estatales. El primer caso trata la definición del potencial electorado para un plebiscito, mientras que el segundo evalúa la valides de una edad obligatoria para el retiro de una cierta clase de individuos. Respecto del primero, en Gillot et al. v. Francia, el Comité tenía que resolver una disputa en relación con las reglas electorales para plebiscitos de autodeterminación de Nueva Caledonia ${ }^{163}$. Tal como hemos apuntado más arriba, el Comité sostuvo que "la evaluación de cualquier restricción debe ser considerada caso a caso, teniendo en cuenta el objeto particular de dicha restricción y el principio de proporcionalidad"164. En relación con las reglas para uno de los plebiscitos, había dos hipótesis diferentes. Primero, las personas que podían votar y las que no. Segundo, entre quienes podían votar, se distinguía según si existían vínculos "suficientemente fuertes con el territorio" en cuestión ${ }^{165}$. El principal criterio empleado era el período de residencia en Nueva Caledonia, con distintas reglas específicas que tomaban en consideración la fecha de nacimiento de la persona, entre otros factores. El Comité pasó a examinar la objetividad y razonabilidad. El requisito de residencia fue estimado, por el Comité, como un factor objetivo, puesto que permitía "tratar de forma diferente a personas en situaciones objetivamente diferentes" considerando sus vínculos con el territorio que debía decidir sobre su autodeterminación ${ }^{166}$. Si bien el plazo de residencia exigido excluía a un $7,67 \%$ de los votantes de Caledonia, se aplicó un tratamiento objetivo que no diferenciaba sobre la base de gru-

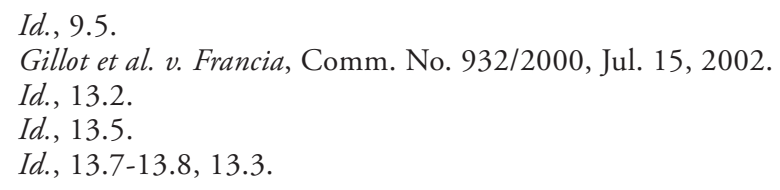


pos étnicos o por origen nacional ${ }^{167}$. En sede de razonabilidad, el Comité asume parte de la argumentación del Estado. Sostuvo que el "artículo 25 del Pacto debe ser considerado en conexión con el artículo 1. Por lo tanto, considera que los criterios establecidos son razonables en el entendido que aplicados única y estrictamente a las votaciones en el marco del proceso de autodeterminación. Tales criterios, en consecuencia, pueden ser justificados solo en relación con el artículo 1 del Pacto, cuestión que hace el Estado Parte"168. Se concluye que exigir "vínculos suficientemente fuertes" de una persona con un territorio no sería irracional ni desproporcionado $^{169}$. El Comité también confirmó que distintas reglas sobre la duración de la residencia eran compatibles con el Pacto, respaldando la decisión del Estado Parte de favorecer a los residentes de largo plazo para efectos de la votación ${ }^{170}$.

La segunda situación en donde podemos identificar nichos de discreción nacional versa sobre la imposición de una edad de retiro obligado para pilotos. En el famoso caso Love et al. Australia, la regla específica fue testeada bajo el artículo 26 del Pacto ${ }^{171}$. El Estado Parte alegó que el límite de edad era justificado por razones de seguridad, respaldado por la evidencia científica, aspectos del régimen de seguridad social y en general por la política de empleo del país ${ }^{172}$. Nuevamente, la argumentación del Comité está fuertemente condicionada por la posición del Estado. Primero, admite que los "sistemas de jubilación obligatoria pueden incluir una dimensión de protección a los trabajadores al limitar los años de vida laboral, en particular, cuando existen esquemas de servicios sociales comprensivos que aseguran la subsistencia de quienes han alcanzado dicha edad"173. Segundo, reconoció que "tal como el Estado Parte notó, el objetivo de maximizar la seguridad de los pasajeros, tripulación y de personas que pueden ser afectadas por el vuelo, constituía una finalidad legítima bajo el Pacto"174. Para evaluar la objetividad y razonabilidad de la medida, el Comité se basó en la "extendida práctica nacional e internacional [...] de imponer una edad de jubilación obligatoria"175. El factor del consenso, por tanto, es determinante para la apreciación que hace el Comité respaldando la tesis del Estado parte. Ambas consideraciones fueron lo suficientemente persuasivas para validar la discreción de las autoridades

\footnotetext{
167 Id., 13.9, 13.11. En ese porcentaje, se excluía un grupo minoritario de provenientes de Francia metropolitana, Polinesia, Wallis, Futuna, las Antillas francesas e isleños del Pacífico. Id., 13.16 . 
nacionales en medidas que buscaban asegurar estándares de seguridad aérea y fomentar una política de empleo.

En los casos en que el Comité descansa en la argumentación del Estado Parte para validar un trato diferenciado, es razonable sostener que actúa de manera deferente. Primero, porque su jurisprudencia no presenta particularidades especiales respecto del estándar de escrutinio aplicado. A diferencia de casos de discurso político, en estas materias no hay referencias a un especial cuidado o a un "estricto test de justificación"176. Al contrario, la estrategia argumentativa de apoyarse y validar los argumentos del Estado Parte parece favorecer un estándar laxo de examinación. Segundo, en materia de igualdad, las consideraciones que se adoptan a nivel local o nacional para una diferenciación, parecen estar respaldadas a nivel internacional por el Comité en razón de los déficits epistémicos que cuenta para tener una mejor apreciación de los efectos de la diferenciación. En esto, la estructura subsidiaria de protección internacional de derechos humanos tiene cierta justificación para un estándar más deferente. El Comité dejaría que los Estados Parte hagan las apreciaciones específicas sobre criterios como el lapso de residencia, para efectos de estructurar un plebiscito de autodeterminación. Los test de objetividad, razonabilidad y proporcionalidad. Tercero, y conectado con lo anterior, el consenso es un factor que permite estructurar un estándar de escrutinio que puede o no validar una restricción o, en casos de igualdad, una diferenciación. En Love, una práctica extendida y generalizada favorece la deferencia a la validez de dicha medida. El Comité descansa en tal consideración para estimarla como un uso compatible con el Pacto.

\section{CONCLUSIÓN}

La jurisprudencia del Comité de Derechos Humanos permite analizar diferentes estándares de deferencia internacional y de discrecionalidad nacional, autorizados por el Pacto. Pese a que el uso de la doctrina del MDA es -al menos en su literalidad- excepcional, el Comité ha resuelto casos acomodando sus estándares de escrutinio, según el tipo de derecho afectado y las razones que justifican la limitación. Este estudio es una reconstrucción inicial de las Observaciones del Comité. Sin embargo, es problemática la identificación clara de los distintos niveles de discrecionalidad nacional. La aproximación casuística ha favorecido un cuerpo jurisprudencial asistemático en la interpretación del Pacto y la intensidad del escrutinio internacional aplicado por el Comité.

176 Véase supra 2.3. 
No obstante, algunas conclusiones preliminares pueden ser presentadas. Primero, el Comité no ha incorporado explícitamente la doctrina europea del MDA. Ello no significa, necesariamente, que sus Observaciones no reconozcan esferas de discreción nacional. Por el contrario, el Comité ha optado por un curso autónomo de acción de definir en cada caso las categorías dogmáticas para la deferencia internacional. Un ejemplo de este camino propio, en materia de derechos de las minorías, es el test de "impacto limitado". Por otra parte, haberse negado a conceder "discrecionalidad sin límites" en materia de seguridad nacional, también demuestra este punto. Por último, el Comité ha abandonado el test de "margen de discreción" que empleó en el caso Hertzberg. Todo esto confirma que el Comité evita comprometerse con un único estándar o doctrina de deferencia internacional.

En otro orden de ideas, el Comité tiene un método similar a las cortes regionales de derechos humanos a la hora de revisar la validez de las restricciones a dichos derechos. El Comité ha elaborado un set tripartito de requisitos: las restricciones deben estar previstas en la ley, deben perseguir una finalidad legítima bajo el Pacto y deben ser necesarias para alcanzar tal objetivo. Las comunicaciones que abordan potenciales violaciones a la libertad de expresión o de religión son examinadas bajo este estándar. En el análisis de necesidad y proporcionalidad, el Comité puede brindar deferencia a los Estados Parte. Algunas diferencias respecto de la intensidad del escrutinio judicial pueden ser identificadas. Por ejemplo, el estándar internacional revisa cuidadosamente las restricciones al discurso político, mientras que las prohibiciones dirigidas a combatir el discurso de odio suele ser examinadas de modo deferencial.

\section{BIBLIOGRAFÍA}

- Acosta et al. (coord.) (2012). El margen de apreciación en el sistema interamericano de Derechos Humanos: proyecciones regionales $y$ nacionales. México: Instituto de investigaciones jurídicas UNAM, $385 \mathrm{pp}$.

- Arai-Takahashi, Yutaka (2006). "The system of restrictions", Theory and practice of the European Convention of Human Rights (Peter van Dijk et al., eds., 4th ed.): pp. 342-8.

- Arai-Takahashi, Yutaka (2002). The margin of appreciation Doctrine and the Principle of Proportionality in the Jurisprudence of the ECHR. Oxford: Intersentia, $145 \mathrm{pp}$.

- Benvenisti, Eyal (1999). "Margin of appreciation, consensus and universal standards", New York University Journal of International Law and Politics, Vol. 31: pp. 843-854. Disponible en http://www. 
pict-pcti.org/publications/PICT_articles/JILP/Benvenisti.pdf. [fecha de consulta: 2 de noviembre de 2013].

- Brage, Joaquín (2005). "Aproximación a una Teoría General de los Derechos Fundamentales en el Convenio Europeo de Derechos Humanos". Revista Española de Derecho Constitucional, núm. 74, mayo-agosto, pp. 111-138. Disponible en: http://www.geocities. ws/derechoconstitucional/teoriacedh.pdf [fecha de consulta: 2 de noviembre de 2013].

- Conte, Alex; Burchill, Richard (2009) Defining civil and political rights: The jurisprudence of the United Nations Human Rights Committee, $2^{\text {nd }}$ ed. London, Ashgate Publishing, 257 pp.

- Contreras, Pablo (2012). "National discretion and international deference in the restriction of human rights: a comparison between the jurisprudence of the European and the Inter-American court of human rights" Northwestern Journal of International Human Rights: pp. 28-82. Disponible en http://scholarlycommons.law. northwestern.edu/cgi/viewcontent.cgi? article $=1155 \&$ context $=$ njihr [fecha de consulta: 2 de noviembre de 2013].

- Davidson, Scott (2002). Intention and effect: The legal status of the final views of the Human Rights Committee, in Litigating Rights. Perspectives from domestic and International Law. Oxford: Hart Publishing, 354 pp.

- García Roca, Javier (2007). "La muy discrecional doctrina del margen de apreciación nacional según el Tribunal Europeo de Derechos Humanos: Soberanía e Integración”. Teoría y Realidad Constitucional. Vol. 20.117-143pp.

- Gandhi, P.R. (1998). The human rights committee and the right of individual communication: law and practice. London: Dartmouth Pub Co., 522 pp.

- Helfer, Laurence; Slaughter, Anne-Marie (1997). "Toward a theory of effective supranational adjudication", Yale L.J., Vol. 107: pp. 273-351

- Humphrey, John (1976). "The international bill of rights: scope and implementation”, Wm. \& Mary L. Rev., Vol. 17. pp. 527.

- Kabasakal, Zehra (2006). "Forging a Global Culture of Human Rights: Origins and Prospects of the International Bill of Rights", Hum. Rts. Q., Vol. 28: pp. 416.

- LEgG, Andrew (2012). The margin of appreciation in international Human Rights Law, deference and proportionality. Oxford: Monographs in International Law, 272 pp.

- Letsas, George (2006). "Two concepts of the margin of appreciation". Oxford Journal of Legal Studies. Vol. 26, pp. 705-732. 
- MacKay, Fergus (2001). "Guía sobre los derechos de los pueblos indígenas y el comité de los derechos humanos de las Naciones Unidas". Disponible en: <http://odhpi.org/wp-content/ uploads/2012/08/COMITE-DDHH-Y-PUEBLOS-INDIGENAS. pdf $>$ [fecha de consulta: 4 de julio de 2013], 56 pp.

- Mutua, Makau wa (1998). "Looking Past the Human Rights Committee: An Argument for De-Marginalizing Enforcement". Buffalo Human Rights Law Review. Vol. 4, pp. 211-260.

- Nowak Manfred (1993). U.N. Covenant on Civil and Political Rights: CCPR Commentary XXXIX, 710 pp.

- Shany, Yuval (2006). "Toward a general margin of appreciation doctrine", International Law European Journal of International Law, Vol. 16: 907-929 pp. Disponible en: http://www.ejil.org/ pdfs/16/5/330.pdf [fecha de consulta: 2 de noviembre de 2013].

- Young, Kirsten (2002). The Law and Process of the U.N, Human Rights Committee. Washington D.C., Hotei Publishing, 400 pp.

- Yourow, Charles (1996). The Margin of appreciation doctrine in the Dynamics of European Human Rights Jurisprudence. Londres: Ed. Kluwer Law International, 196 pp. 